\title{
Sea ice in the Barents Sea: seasonal to interannual variability and climate feedbacks in a global coupled model
}

\author{
Torben Koenigk · Uwe Mikolajewicz • \\ Johann H. Jungclaus · Alexandra Kroll
}

Received: 9 January 2008/Accepted: 14 July 2008/Published online: 22 August 2008

(c) The Author(s) 2008. This article is published with open access at Springerlink.com

\begin{abstract}
Sea ice variability in the Barents Sea and its impact on climate are analyzed using a 465-year control integration of a global coupled atmosphere-ocean-sea ice model. Sensitivity simulations are performed to investigate the response to an isolated sea ice anomaly in the Barents Sea. The interannual variability of sea ice volume in the Barents Sea is mainly determined by variations in sea ice import into Barents Sea from the Central Arctic. This import is primarily driven by the local wind field. Horizontal oceanic heat transport into the Barents Sea is of minor importance for interannual sea ice variations but is important on longer time scales. Events with strong positive sea ice anomalies in the Barents Sea are due to accumulation of sea ice by enhanced sea ice imports and related NAO-like pressure conditions in the years before the event. Sea ice volume and concentration stay above normal in the Barents Sea for about 2 years after an event. This strongly increases the albedo and reduces the ocean heat release to the atmosphere. Consequently, air temperature is much colder than usual in the Barents Sea and surrounding areas. Precipitation is decreased and sea level pressure in the Barents Sea is anomalously high. The largescale atmospheric response is limited with the main impact being a reduced pressure over Scandinavia in the year after a large ice volume occurs in the Barents Sea. Furthermore, high sea ice volume in the Barents Sea leads to increased sea ice melting and hence reduced surface salinity.
\end{abstract}

Electronic supplementary material The online version of this article (doi:10.1007/s00382-008-0450-2) contains supplementary material, which is available to authorized users.

T. Koenigk ( $₫)$ · U. Mikolajewicz · J. H. Jungclaus · A. Kroll Max-Planck-Institut für Meteorologie, Bundesstraße 53, 20146 Hamburg, Germany

e-mail: torben.koenigk@smhi.se
Generally, the climate response is smallest in summer and largest in winter and spring.

Keywords Sea ice variability - Barents Sea . Arctic climate $\cdot$ Seasonal to interannual climate variability . Global coupled atmosphere-ocean modeling . Coupled atmosphere-ocean-sea ice processes

\section{Introduction}

The Arctic plays an important role for the global climate system. Sea ice restricts exchange processes between ocean and atmosphere. Due to its high albedo sea ice absorbs considerably less solar radiation than the open ocean. Furthermore, small changes in sea ice concentration strongly affect the ocean heat release to the atmosphere. Largest variations in sea ice cover occur in regions with seasonal ice cover. A number of studies analyzed observational data sets and historical ice observations and showed that the Barents Sea that is bordered by Svalbard, Franz Josef Land, Novaya Zemlya and northern Norway is one of the Arctic regions with largest sea ice variability at different time scales (Deser et al. 2000; Shapiro et al. 2003; Vinje 2001; Divine and Dick 2006). Since air-sea temperature differences in the Barents Sea are extremely large, ocean heat releases reach values of $300-500 \mathrm{~W} / \mathrm{m}^{2}$ (Simonsen and Haugan 1996). One can expect that sea ice variability in the Barents Sea highly influences the heat release and hence local and maybe large-scale climate conditions. This would provide a potential for climate predictability.

Modeling studies by Delworth et al. (1997) and Jungclaus et al. (2005) suggest that multi-decadal variability in the North Atlantic meridional overturning 
circulation (MOC) strongly affects sea ice in the Arctic and particularly in the Barents Sea. Enhanced oceanic heat transport into the Barents Sea is connected with an above normal MOC and causes a reduction of sea ice.

A number of studies investigated the impact of the atmospheric circulation on Arctic sea ice variability. Kimura and Wakatsuchi (2001) showed that daily variations in sea ice extent in the Barents Sea are governed by sea ice advection due to wind variations. Kwok et al. (2005) analyzed a 10-year record of sea ice motion and thickness from satellites and attributed high Arctic ice exports into Barents Sea to anomalously low sea level pressure (SLP) over the eastern Barents Sea. Yamamoto et al. (2006), Wang et al. (2004) and Liu et al. (2004) analyzed the impact of the North Atlantic Oscillation (NAO) and Arctic Oscillation (AO) on sea ice. They found less sea ice and warmer air and ocean temperature in the Barents Sea during positive NAO/AO-phases due to enhanced atmospheric and oceanic heat transports.

Observations show a substantial reduction of Arctic sea ice in the last 30 years. The largest decrease of sea ice extent has been observed in Barents and Kara Seas with about $-10 \% / d e c a d e$ since the late $70 \mathrm{~s}$ (Parkinson et al. 1999). The high NAO years since the end of the $80 \mathrm{~s}$ contributed to the observed Arctic sea ice reduction but cannot fully explain this trend (Liu et al. 2004; Overland and Wang 2005). Future scenario simulations predict a further decrease of sea ice in the Barents Sea in the next decades (Holland and Bitz 2003; Koenigk et al. 2007). Probably, the Barents Sea will be the first Arctic region without winter sea ice. This will imply large changes in ocean-atmosphere exchanges and might impact the largescale atmospheric circulation. Several recent model studies showed that sea ice anomalies may affect atmospheric climate conditions and can modulate large-scale atmospheric modes as the NAO (Magnusdottir et al. 2004; Alexander et al. 2004; Kvamstö et al. 2004; Koenigk et al. 2006).

Changes in the Arctic/North Atlantic climate system are also associated with changes in the ecosystem as Drinkwater (2006) demonstrated on the basis of the warming in the North Atlantic in the1920s and 1930s.

In this study, the global coupled atmosphere-ocean-sea ice model ECHAM5/MPI-OM (European Center for Medium Range Weather Forecasts Hamburg/Max-PlanckInstitute Ocean Model) is used to investigate the natural seasonal to interannual variability of sea ice in the Barents Sea and its impact on climate. Figure 1 shows the area defined as Barents Sea in this study. A control integration of nearly 500 years with preindustrial external forcing allows statistical analyses at different timescales and more general statements about physical processes than is possible with comparatively short time series of observations and reanalyses. Additionally, using a fully coupled atmosphere-ocean sea ice model enables us to study feedback mechanisms among these climate components which is highly relevant in the light of the recent sea ice reduction and future climate development.

The article is organized as follows. We briefly introduce the model in Sect. 2 before we present the results from the control integration of the model in Sect. 3. In the fourth chapter sensitivity simulations are discussed and we summarize and conclude in Sect. 5.

\section{Model description}

The numerical experiment analyzed here is the control integration carried out for the International Panel on Climate Change's Fourth Assessment Report using the Max-Planck-Institute for Meteorology global atmosphereocean-sea ice model ECHAM5/MPI-OM. The atmosphere model ECHAM5 (Roeckner et al. 2003) is run at T63 resolution, which corresponds to a horizontal resolution of about $1.875^{\circ} \times 1.875^{\circ}$. It has 31 vertical levels up to $10 \mathrm{hPa}$. The ocean model MPI-OM (Marsland et al. 2003) includes a Hibler-type dynamic-thermodynamic sea ice model with viscous-plastic rheology (Hibler 1979). The ocean grid is an Arakawa C-grid and allows for an arbitrary placement of the grid poles. In this setup, the model's North and South Pole are shifted to Greenland and to the center of Antarctica (c.f., Jungclaus et al. 2006; Fig. 1). and the grid spacing varies between about $15 \mathrm{~km}$ around Greenland and $184 \mathrm{~km}$ in the tropical Pacific. In the vertical, there are 40 unevenly spaced levels.

The atmosphere model and the sea ice-ocean model are coupled by the OASIS coupler (Valcke et al. 2003). The coupler transfers fluxes of momentum, heat, and freshwater from the atmosphere to the ocean and performs the interpolation onto the ocean grid. Additionally, the coupler transmits sea surface temperature, sea ice thickness and concentration, snow thickness and surface velocity from the ocean to the atmosphere. The climate model includes a river runoff scheme (Hagemann and Dümenil 1998; Hagemann and Dümenil-Gates 2003). The river runoff is transferred to the ocean together with the precipitation. Glacier calving is included such that any snow falling on Greenland and Antarctica is instantaneously transferred to the nearest ocean grid point. Hence, the mass balance of glacier ice sheets is not accounted for. In the coupled model, no flux adjustment is used.

The simulated mean climate and variability characteristics of the 465-year pre-industrial control experiment analyzed here are similar to the simulation under presentday greenhouse gas forcing discussed in Jungclaus et al. (2006). Koenigk et al. (2007) investigated future Arctic 


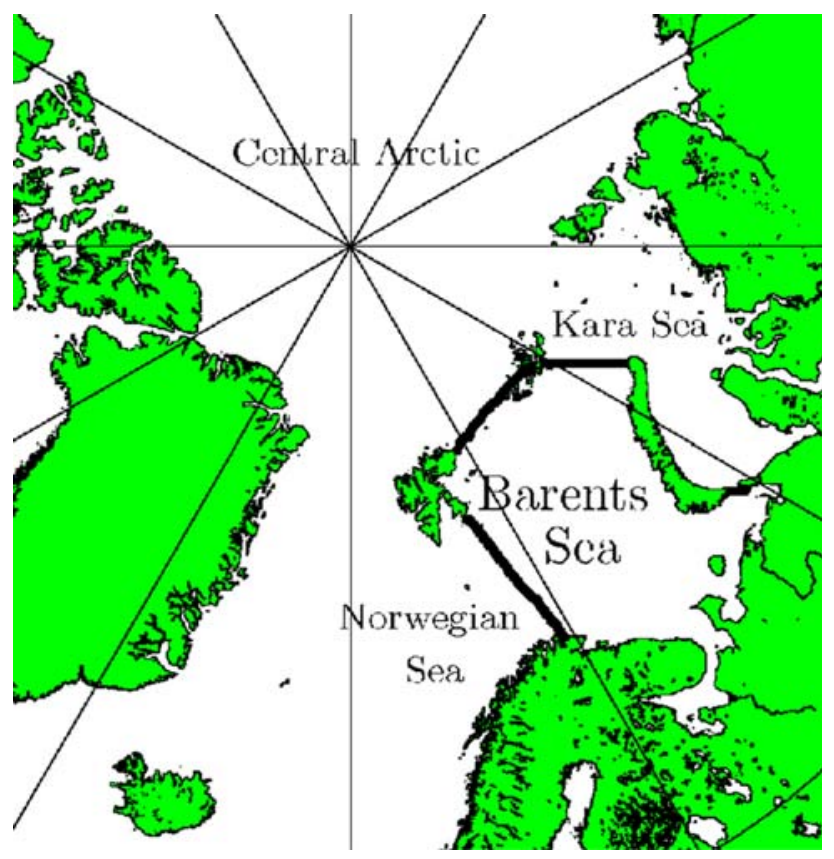

Fig. 1 Map of Barents Sea and surroundings. The black lines indicate the margins of the area analyzed in this study

freshwater exports using the same model setup. Sea ice conditions in the Arctic are relatively well simulated compared to satellite observations by Johannessen et al. (2002). Figure $2 \mathrm{a}$ shows the average number of months with a sea ice concentration exceeding $15 \%$. The model has slightly too thick ice along the Siberian coast and thus too high summer ice concentration in this area. Sea ice conditions in the Barents Sea are realistically simulated in the control integration.

In addition to the control integration, a set of sensitivity experiments has been performed to analyze the climate response to heavy sea ice conditions in the Barents Sea. These experiments are described in detail in Sect. 4.

\section{Results}

\subsection{Variability of sea ice in the Barents Sea}

In this section, sea ice variability in the Barents Sea and the formation of particularly strong and weak sea ice conditions are analyzed by using the control integration of the model. The Barents Sea is a transition zone with no ice at all in the southwest and permanent ice cover in the northernmost part (Fig. 2a). The first empirical orthogonal function (EOF) of annual mean sea ice concentration in the control integration explains $26.4 \%$ of the variance of northern hemispheric sea ice concentration (Fig. 2b). The first EOF is dominated by a dipole with one center over the Barents, Kara and Greenland Seas and the other over the Labrador Sea. The pattern is similar to EOF 1 of 40-year winter data from the National Snow and Ice Data Center (Deser et al. 2000). Compared to our study, Deser et al. (2000) found a slightly higher explained variance (35\%) and largest variability in the Greenland Sea while our simulations show largest variations in the Barents Sea. This might be due to the fact that Deser et al. (2000) analyzed winter means while we use annual means. The time series of our EOF 1 is highly correlated with both sea ice extent $(r=0.94)$ and sea ice volume in the Barents Sea (IVB, $r=0.96$ ). The correlation with the total northern hemispheric sea ice extent is 0.81 indicating the importance of sea ice variations in the Barents Sea. This agrees with results by Bengtsson et al. (2004) who performed sensitivity simulations with both AGCM and AOGCM to analyze the impact of sea ice change on Arctic surface air temperature (SAT, mean of $70-90^{\circ} \mathrm{N}$ ). They found that reduced sea ice concentration particularly in the Barents Sea is the main reason for increased Arctic temperature. Also, Goosse and Holland (2005) showed that Arctic SAT variability is highly related to sea ice concentration and surface air temperature (SAT) in the Barents and Kara Seas by analyzing a 650-year simulation with an AOGCM.
Fig. 2 a Mean number of months per year with a sea ice concentration exceeding $15 \%$. b EOF 1 of annual mean sea ice concentration in the northern hemisphere a) ice cover

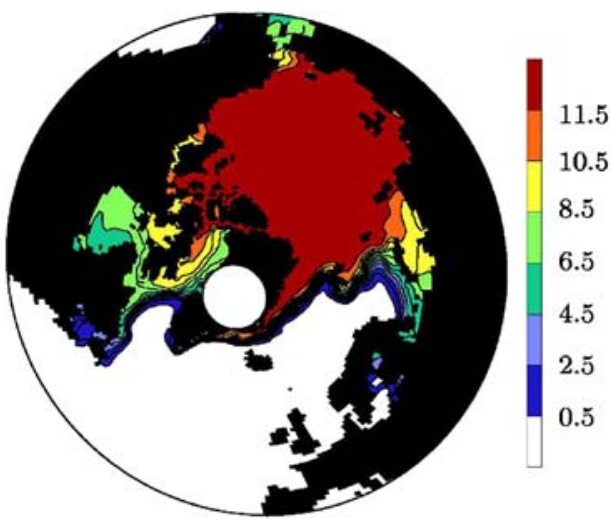

b) $\mathrm{EOF} 1,26.4 \%$

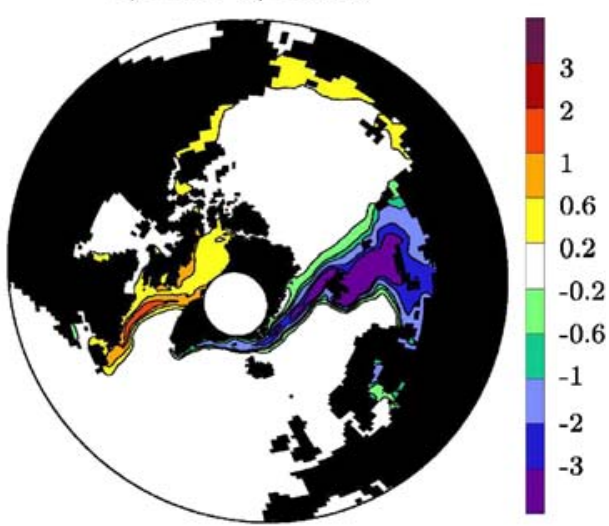


Our simulations of the annual mean sea ice volume of the Barents Sea (Fig. 3) show a high variability at interannual to multi-decadal timescales with peaks exceeding 95\% significance at about 2.5, 5.5, 9 and 20 years (Fig. 4). Annual mean values of IVB in our control integration vary between $0.5 \times 10^{11}$ and $7 \times 10^{11} \mathrm{~m}^{3}$. Many other studies analyzing Arctic climate and sea ice variability found peaks at roughly 10 years. Mysak and Venegas (1998) suggested a 10-year climate cycle in the Arctic, which should be characterized by a clockwise propagation of sea ice anomalies through the Arctic and a coexisting standing oscillation in sea level pressure (SLP) anomalies. A similar mechanism is responsible for decadal variations in the Fram Strait sea ice export (Koenigk et al. 2006, 2008). Polyakov and Johnson (2000) analyzed NCEP/NCAR reanalysis data and related decadal sea ice variations to decadal variations in the AO. A similar variation has been found by Hilmer and Lemke (2000). However, our model control integration does not show a significant decadal variability of the AO.

Other studies found significant variability on longer time scales. Goosse et al. (2002) used a global coupled climate model and found a dominant peak at 15-20 years in Arctic sea ice volume. Divine and Dick (2006) found a 20-30year-oscillation in historical data of Greenland and Barents Seas sea ice edge. These authors (2006) also showed a strong seasonal cycle of the ice edge with only little ice left in the Barents Sea in August. Our simulations show similar results. IVB is at maximum in late spring with up to $1 \times 10^{12} \mathrm{~m}^{3}$ and at minimum in late summer/early autumn where sea ice disappears in several years of the control integration. However, standard deviations of seasonal IVB are large in all seasons and vary between $0.98 \times 10^{11} \mathrm{~m}^{3}$ in autumn and $1.57 \times 10^{11} \mathrm{~m}^{3}$ in spring. The correlation between IVB in one season and the following three seasons reaches about $0.75,0.5$ and 0.3 independent of the starting season. Hence, both summer and winter IVB depend partly on the amount of IVB of the preceding seasons. The autocorrelation of annual mean IVB is 0.51 and 0.22 for a lag of 1 and 2 years, respectively.

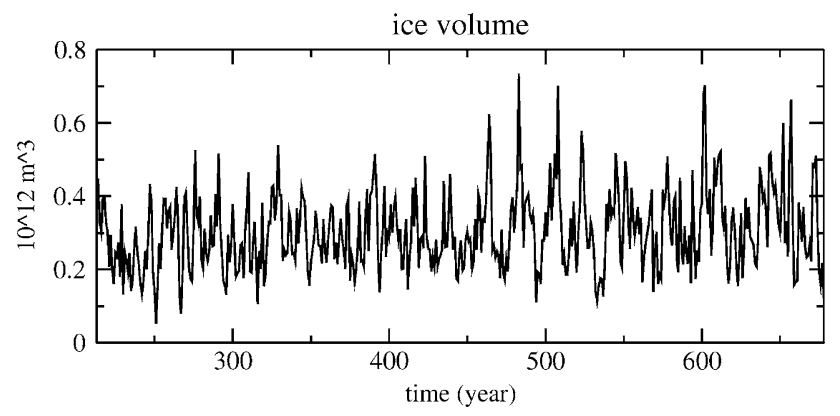

Fig. 3 Time series of annual mean sea ice volume in the Barents Sea in $10^{12} \mathrm{~m}^{3}$
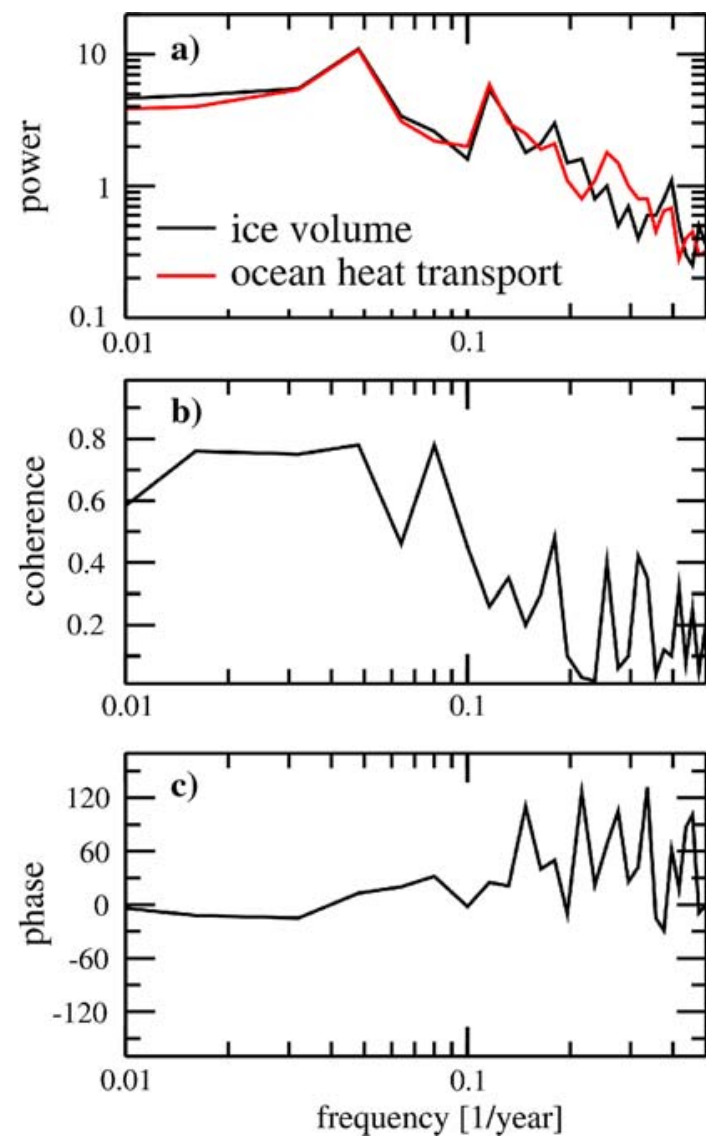

Fig. 4 Cross spectrum analysis of normalized annual values of sea ice volume of the Barents Sea and ocean heat transport into the Barents Sea. a Power spectrum, b coherence spectrum, c phase spectrum

The annual rate of change of IVB is determined by transport of sea ice across the boundaries of the Barents Sea and melting and freezing of sea ice within the Barents Sea (Table 1) within one year. The mean ice transports in the Barents Sea and vicinity in our control integration are shown in Fig. 5. The sea ice transport across the boundaries of the Barents Sea with Kara Sea and Central Arctic is mainly directed towards Barents Sea (in the following we call this ice import although it can get negative). The mean annual sea ice import into the Barents Sea amounts to $0.87 \times 10^{12} \mathrm{~m}^{3} /$ year in the control integration. Kwok et al. (2005) used satellite measurements to estimate the winter ice volume transport across the line Svalbard-Franz Josef Land between 1994-2003. They found a mean ice volume transport of $0.04 \times 10^{12} \mathrm{~m}^{3} /$ winter. However, the difference to our study is probably not as large as the numbers suggest because Kwok et al. (2005) did not consider the entire year and analyzed only about half of the border to Barents Sea. In our model, about $60 \%$ of the ice import into the Barents Sea takes place between Svalbard and Franz Josef Land. The rest is mainly imported between Franz 
Josef Land and Novaya Zemlya and a small part through the Kara Strait into the Barents Sea. Additionally, Kwok et al. used a rather short time period, which was dominated by strongly positive NAO. Our simulations show a reduction of the ice import into Barents Sea by about $30-50 \%$ in high NAO-years since anomalously southerly winds occur between Svalbard and Franz Josef Land (Fig. 6). The variability of annual export in our simulation is very high with a standard deviation of $0.33 \times 10^{12} \mathrm{~m}^{3} /$ year. Maximum and minimum ice imports are $2.06 \times 10^{12}$ and $-0.25 \times 10^{12} \mathrm{~m}^{3} /$ year. Nevertheless, our model overestimates the ice import into the Barents Sea. The ice transport across the southern and western boundaries is normally directed towards Greenland and Norwegian Seas and takes mainly place south of Svalbard (we call this ice export). Hence, the convergence of sea ice transport in the Barents Sea (import minus export) is governed by the import (correlation between import and convergence is 0.90).

The annual rate of change of IVB depends strongly on the convergence of sea ice transport into the Barents Sea $(r=0.70)$ and therefore on the import $(r=0.57)$. Thermodynamics play only a minor role for interannual variability of IVB. The correlation of the thermodynamic sea ice volume change (calculated as residuum from the convergence of sea ice transport in the Barents Sea and rate of IVB change within 1 year) with rate of change of IVB is -0.31 and with the import -0.84 . Hence, large sea ice imports into the Barents Sea are related to strong melting of sea ice in the Barents Sea. The reason is that more sea ice reaches areas where ocean temperatures are normally above the freezing level and hence a larger amount of sea ice can be melted. This also explains why the year-to-year rate of change of IVB is rather small compared to changes in the ice import and thermodynamic ice volume changes. Correlations between annual mean IVB itself and ice transports are similar to the values above-mentioned.

The ice transport into the Barents Sea is mainly dominated by the local wind stress. It is highly correlated with the SLP-gradient between northern Svalbard and northern Novaya Zemlya $(r=0.79)$. Anomalously high pressure over Svalbard and below normal pressure over Novaya Zemlya lead to anomalously northerly winds, which

Table 1 Means, maximum and minimum values, and standard deviations of rate of sea ice volume change (rate of ice vol. change), ice transport over northern and eastern border of Barents Sea (ice

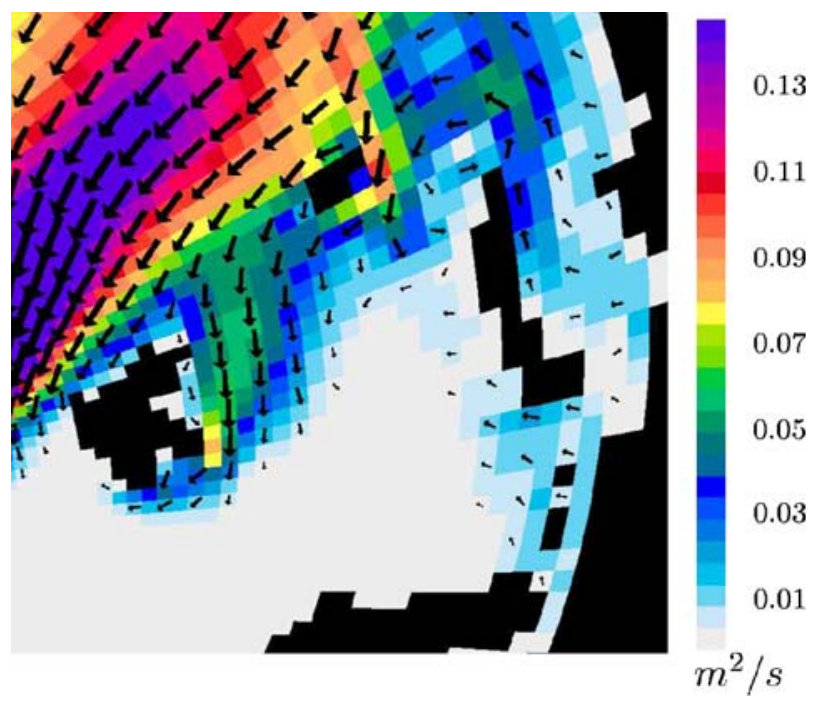

Fig. 5 Annual mean sea ice transport in the Barents Sea and vicinity in $\mathrm{m}^{2} / \mathrm{s}$

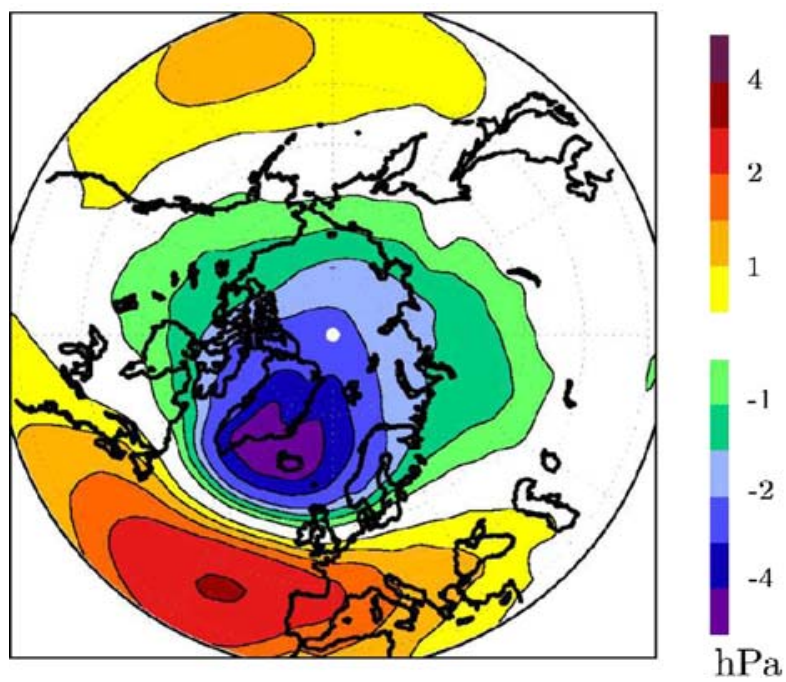

Fig. 6 Regression analysis between winter (DJF) NAO-index and winter $\mathrm{SLP}$ in $\mathrm{hPa}$ /standard deviation $\mathrm{NAO}$-index

transport much ice into the Barents Sea. A cross-correlation analysis between the SLP-gradient between Svalbard and Novaya Zemlya and ice transport into the Barents Sea

import), ice transport over southern and western border (ice export) and freezing minus melting in the control integration in $10^{12} \mathrm{~m}^{3} /$ year

\begin{tabular}{llccrr}
\hline In $10^{12} \mathrm{~m}^{3} /$ year & Rate of ice vol. change & Ice import & Ice export & Import-export & Freezing-melting \\
\hline Mean & $\sim 0$ & 0.87 & 0.20 & 0.67 & -0.67 \\
Max & 0.25 & 2.06 & 0.98 & 1.67 & 0.36 \\
Min & -0.29 & -0.25 & 0 & -0.40 & -1.89 \\
Stddev & 0.11 & 0.33 & 0.15 & 0.27 & 0.26 \\
\hline
\end{tabular}


indicates that the SLP-gradient governs the ice transport at high frequencies below 5 years (not shown).

A lead-lag correlation analysis between annual mean oceanic heat transport into the Barents Sea (OHT) and IVB shows that the highest correlation occurs at lag 0 with 0.56 . Performing the same correlation analyses but for high pass filtered data from 1 to 10 and 1 to 5 years provides correlation coefficients of 0.35 and 0.09 , respectively. Furthermore, the correlation of OHT with the rate of change of IVB is only 0.16 . This and the fact that thermodynamic sea ice volume change is negative in years with a positive total ice volume change indicate that OHT into the Barents Sea plays only a minor role for interannual sea ice variability in the Barents Sea. However, the importance of OHT increases with increasing time scales. This becomes evident in a cross-spectrum analysis between normalized values of IVB and the OHT (Fig. 4). The power spectrums agree nicely for time scales exceeding 5 years. A high coherence between IVB and OHT can be seen at long time scales and the phase difference is continuously near 0 . In contrast, at short time scales no substantial relation occurs between the two time series. A lag-lead correlation analysis between OHT and IVB using a low pass filter eliminating all periods below 10 years shows similar results. The highest correlation coefficient occurs at lag 0 with 0.74 (0.72 if heat flux leads 1 year, 0.70 if IVB leads one year). In contrast to the atmosphere with its strong interannual variability, OHT shows pronounced decadal and longer scale variations and hence governs the IVB at long time scales.

We calculated a lag regression analysis between annual mean heat content of the upper $200 \mathrm{~m}$ and IVB (not shown). During heavy ice conditions in the Barents Sea, the heat content is reduced in the Barents and in the entire Nordic Seas. The heat content of the upper $200 \mathrm{~m}$ spatially integrated over the Barents Sea and IVB are correlated with 0.33. Eleven-year running means of IVB and heat content are correlated with 0.58 . Similar to the heat transport into the Barents Sea, also the heat content shows strongest variability at longer time scales than those considered in this study. However, the correlation between Barents Sea ocean heat content of the upper $200 \mathrm{~m}$ and OHT is only moderate with 0.37 for annual means and 0.46 for 11 -year running means. Decadal variations of the atmosphereocean heat flux will be analyzed in detail in an upcoming study.

Figure 7 shows a lag regression analysis between annual mean IVB and SLP. Four years before IVB is at maximum, a dipole with positive center near Iceland and negative anomalies between Newfoundland and Spain is formed. This pattern intensifies in the following years and is similar to the negative NAO pattern. However, the pattern is slightly shifted to the north and the center of the positive pole is situated over Svalbard, which leads to a strong SLPgradient between Svalbard and Severnaya Zemlya. Hence, ice transport into the Barents Sea is anomalously large in these years and a positive anomaly of IVB is formed. It has to be noted that the autocorrelation of this regression pattern is very low. The pattern should therefore not be understood as a standing pattern, which exists for several years. Analyses of the 15 largest IVB events show that such a pattern normally occurs in one or two of the years before or during the IVB event and transports a huge amount of sea ice into the Barents Sea, where the sea ice volume stays above normal for the next 2 or 3 years. Goosse et al. (2003) performed a very long integration with a coarse resolution OAGCM and analyzed one extreme Arctic ice volume event. This event was mainly characterized by sea ice covering the entire Barents Sea and extending as far south as the Lofot Islands. The atmospheric pattern leading to this ice event is dominated by a positive pressure anomaly over the Norwegian Sea and a negative anomaly over Greenland. This pattern strongly reduces Fram Strait sea ice export and keeps the ice in the Arctic. Additionally, ice transports into the Barents Sea are increased. Although this pressure pattern differs from our regression pattern between SLP and IVB it also includes an enhanced pressure gradient across Barents Sea.

The correlation between annual mean NAO-index and annual mean IVB in our control integration is -0.29 for lag 0 and -0.25 when NAO leads by 1 and 2 years. The correlation for winter values is slightly smaller. The first principal component (PC) of EOF 1 of annual mean sea ice concentration and NAO-index is correlated with -0.33 . Vinje (2001) found that the correlation between winter NAO-index and April sea ice extent in the Barents Sea is time dependent. In the periods 1900-1935 and 1966-1996, the correlation was between -0.5 and -0.6 but much weaker during 1864-1900 $(r=-0.3)$ and 1935-1966 $(r=-0.36)$. Holland (2003) used a global coupled model and found a correlation of 0.59 between NAO-index and EOF 1 of sea ice concentration. Sorteberg and Kvingedal (2006) stated that the wintertime link between NAO and sea ice extent in the Barents Sea is only moderate and not the dominating factor. They showed that cyclones moving from the Nordic Seas to the Arctic and Siberian coast dominate sea ice conditions in the Barents Sea. Obviously, the impact of the NAO on the Barents Sea depends strongly on the exact position of the Iceland Low extension into the Arctic because this extension determines the wind forcing across the boundaries of the Barents Sea.

In correspondence to the atmospheric circulation, the regression analysis between annual mean sea ice thickness in the Arctic and IVB (Fig. 8) shows a small positive ice thickness anomaly in the Laptev Sea and below normal ice thicknesses at the Canadian coast four years before the 
Fig. 7 Lagged regression coefficient between annual mean ice volume in the Barents Sea and SLP anomalies in $\mathrm{hPa}$ per standard deviation ice volume. a Ice volume lags 4 years, b ice volume lags 2 years, $\mathbf{c}$ ice volume lags 1 year, $\mathbf{d}$ lag 0 , e ice volume leads 1 year, $\mathbf{f}$ ice volume leads 2 years a) $\operatorname{lag}-4$ ycars

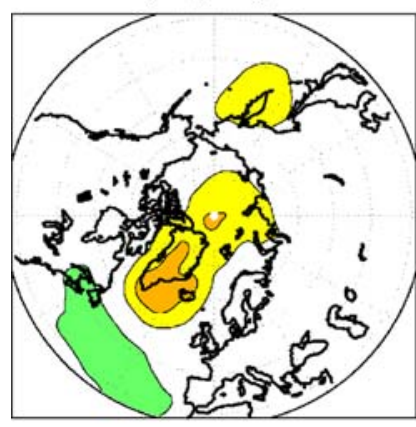

d) $\operatorname{lag} 0$

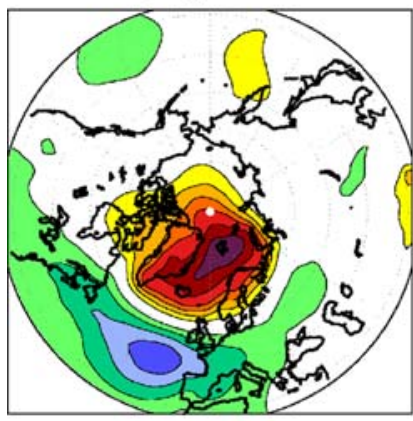

e) lag 1 year
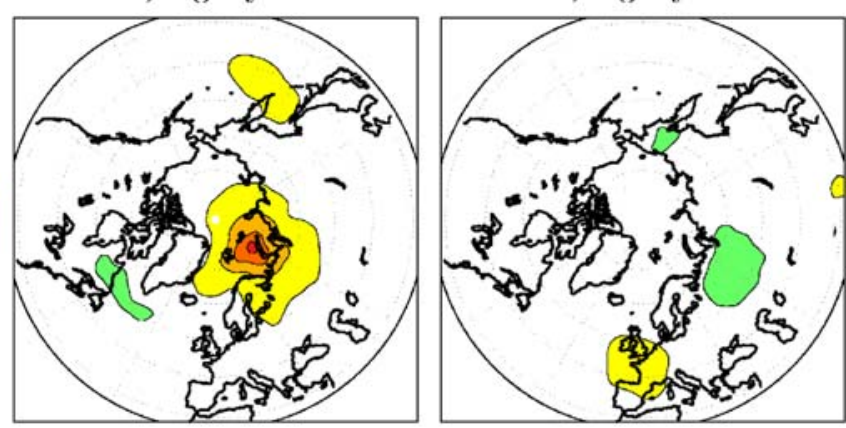

c) $\operatorname{lag}-1$ ycar
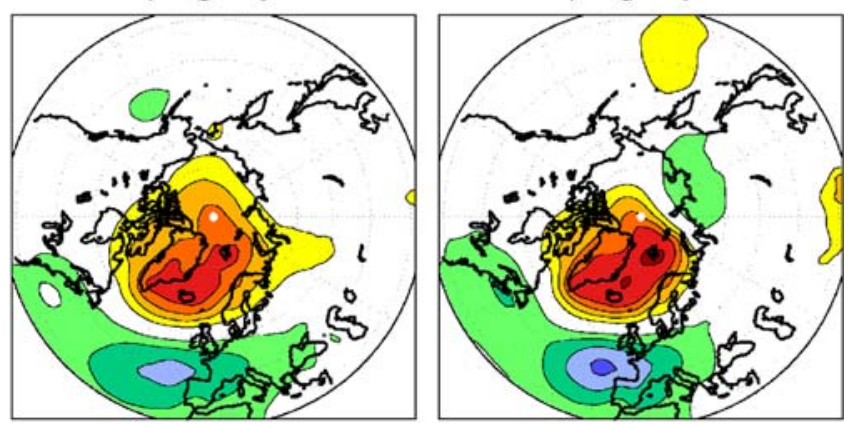

f) lag 2 years

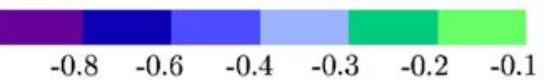

0.1

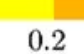

0.3
0.4
$0.6 \quad 0.8$ maximum. In the following years, the wind anomalies lead to increased ice transports from the North American coast across the Arctic towards Barents Sea, Kara Sea and the European Arctic. Sea ice volume in the Barents Sea is accumulated over two to three years until it reaches its maximum. At the same time, sea ice thickness is strongly decreased at the North American coast. Obviously, a several-year-long redistribution of ice in the Arctic due to anomalous atmospheric circulation leads to the formation of the IVB maximum. Again, it has to be noted that this should not be understood as a several year-long continuously anomalous ice transport into the Barents Sea but as increased ice transport in parts of the period before and during the maximum IVB. Sea ice thickness stays above normal for two to three years in the Barents and Kara Sea (Fig. 8e, f) after the maximum while the negative anomaly at the North American coast disappears rather fast.

\subsection{Interannual climate response to sea ice anomalies in the Barents Sea}

To analyze the response of climate conditions to large and small IVB, composite analyses are calculated. All years from the control integration are considered with IVB-anomalies exceeding \pm 1 standard deviation. It has to be noted that it is difficult to discriminate between the climate response to maximum IVB and the climate conditions causing maximum IVB. This difficulty occurs particularly at zero lag. Thereafter, a large part of the anomalies can be associated with the ice anomaly in the Barents Sea.

In the year of maximum IVB, albedo is strongly enhanced in the Barents and western Kara Sea. The center of the anomaly is situated between northwestern Novaya Zemlya and Franz Josef Land), where albedo is increased by up to $20 \%$ due to enhanced sea ice cover. In the following 2 years, albedo increases by up to $15 \%$ and up to $10 \%$, respectively (Fig. 9a, d, h). Hence, absorption of short wave radiation is substantially reduced in the Barents Sea. Laine (2004) analyzed the summer albedo in the Arctic from radiometer data of the period 1982-1998 and showed considerable annual variability in the Barents/Kara Seas. Interestingly, he found a rather small correlation $(r=0.3)$ between summer albedo and sea ice concentration in this area but much higher correlations in most other Arctic areas. In contrast, the correlations between sea ice concentration and albedo, both for summer and annual means averaged over the Barents Sea, exceed 0.9 in our control integration. Although Laine used rather short time series and observations of summer sea ice concentration 
Fig. 8 Lagged regression coefficient between annual mean ice volume in the Barents Sea and ice thickness anomalies in $\mathrm{m}$ per standard deviation ice volume. a Ice volume lags 4 years, $\mathbf{b}$ ice volume lags 2 years, $\mathbf{c}$ ice volume lags 1 year, $\mathbf{d}$ lag 0 , e ice volume leads 1 year, $\mathbf{f}$ ice volume leads 2 years a) lag -4 years

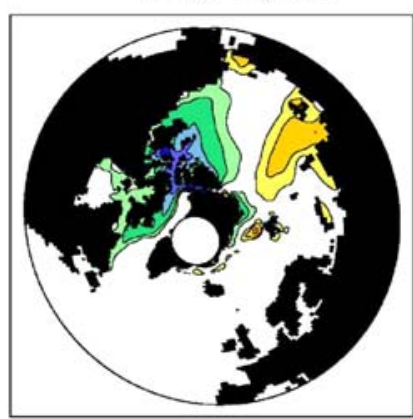

d) lag 0

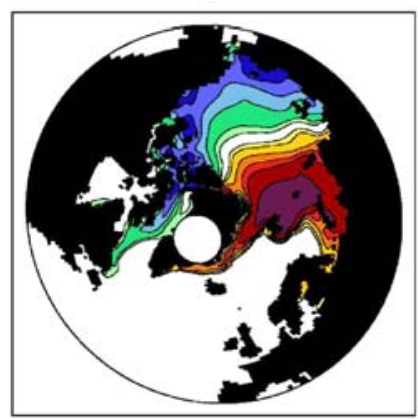

e) lag 1 year
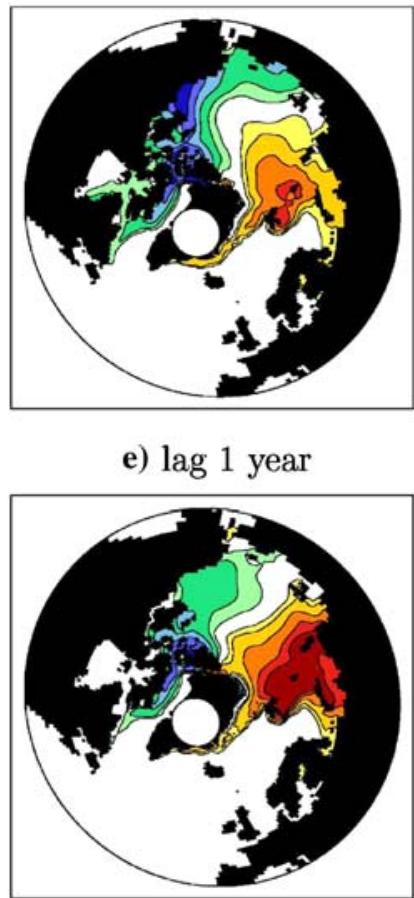

c) lag -1 year

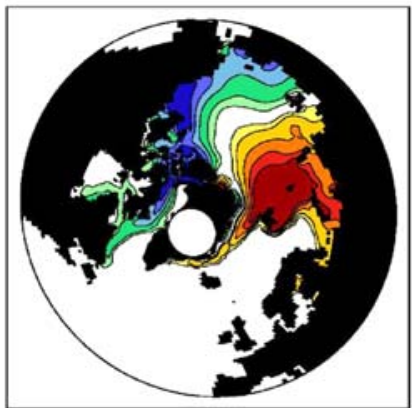

f) lag 2 years
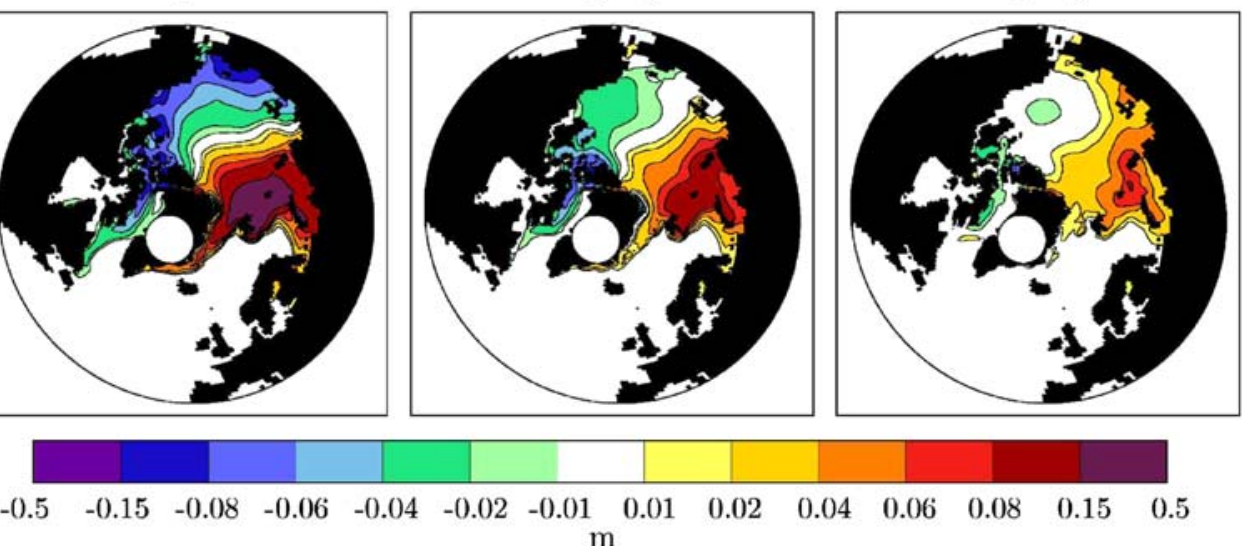

are difficult due to melt-ponds, it seems that our model overestimates the relationship between ice concentration and albedo due to the imposed dependence of surface albedo on sea ice concentration and surface temperature.

The enhanced ice cover and thickness during large IVB strongly reduces the heat flux from ocean to atmosphere (sensible + latent heat flux, not shown). Annual anomalies are largest with up to $-30 \mathrm{~W} / \mathrm{m}^{2}$ between northwestern Novaya Zemlya and Franz Josef Land. During winter, when heat fluxes are particularly large due to large temperature differences between the cold atmosphere and the comparatively warm ocean surface, the average heat flux anomalies reach $-100 \mathrm{~W} / \mathrm{m}^{2}$. The sum of sensible and latent heat flux accounts for about two-third of the total net heat flux anomalies in the Barents Sea while roughly onethird is due to short and long wave radiation flux anomalies.

The strongly reduced ocean heat release in the Barents Sea leads to a local high pressure anomaly (Fig. 7e) one year after the maximum IVB. However, the impact on the large-scale atmospheric circulation is limited. SLP only responds significantly in the Barents Sea.

Near surface air temperature anomalies are particularly large over the Barents Sea. The temperature is reduced by more than $2 \mathrm{~K}$ in years with maximum IVB and is 2 and $1.5 \mathrm{~K}$ colder after one and two years, respectively (Fig. 9b, e, i). In contrast to SLP, the $2 \mathrm{~m}$ air temperature anomaly spreads over large areas of Siberia, northeastern and eastern Europe. Although the response of the atmospheric circulation is rather localized, this anomaly and the mean atmospheric circulation advect the cold air masses over large regions. Wu et al. (2004) analyzed SAT during winters with heavy and light ice conditions in the Greenland-Barents Seas from NCAR/NCEP reanalysis data (Kalnay et al. 1995). They found a large-scale SAT anomaly pattern with sharp local-scale anomalies along the ice edge. They argued that the atmospheric circulation, which is dominant during several heavy and light winters, respectively, is responsible for the large-scale anomalies while the local-scale anomalies are a feedback to the displaced sea ice edge.

Over the northwestern North Atlantic, the simulated temperature is below normal as well. This is connected with a southward displacement of the North Atlantic Current (NAC) and a weakening of the NAC due to reduced westerlies over the North Atlantic during the formation process of the IVB maximum (Fig. 7). Eden and Willebrand (2001) showed that a negative NAO anomaly is associated with a reduction of the strength of the subpolar and subtropical gyre, which goes along with a reduced NAC. The atmospheric forcing over the North Atlantic during the formation of high IVB in our simulations is 
a) albedo, lag 0

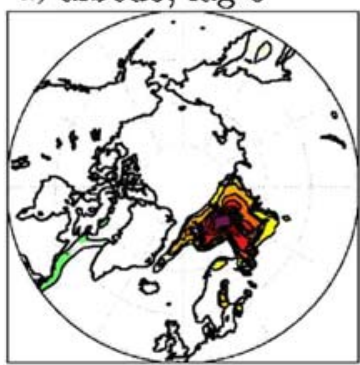

d) albedo, $\operatorname{lag} 1$

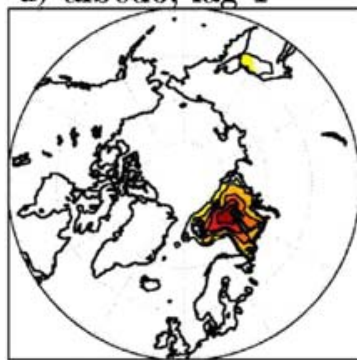

h) albedo, $\operatorname{lag} 2$

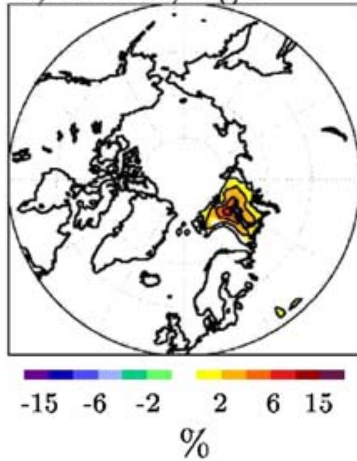

b) $\mathrm{T} 2 \mathrm{~m}, \operatorname{lag} 0$

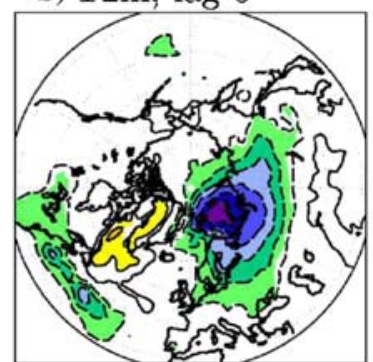

e) $\mathrm{T} 2 \mathrm{~m}, \operatorname{lag} 1$

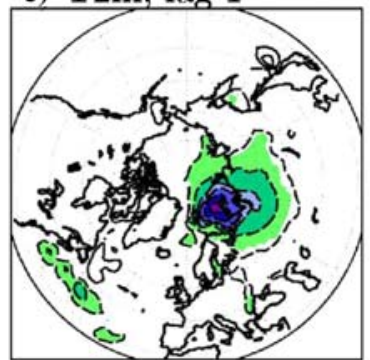

i) $\mathrm{T} 2 \mathrm{~m}, \operatorname{lag} 2$

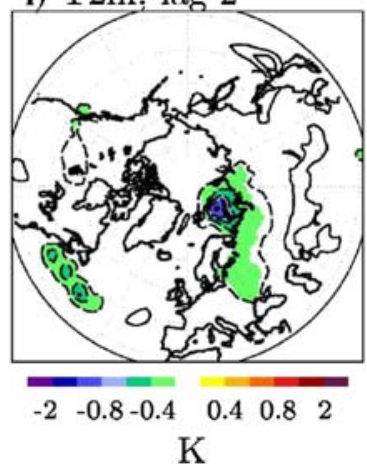

Fig. 9 Anomalies of annual mean albedo (absolute anomalies in \%), $2 \mathrm{~m}$ air temperature (in Kelvin), $850 \mathrm{hPa}$ temperature (in Kelvin) and precipitation (in \%, relative to annual mean value) during years with high Barents Sea ice volume (top), after one (middle) and after two

similar to the negative NAO case analyzed by Eden and Jung (2001). Similar to our results, these authors found negative surface temperature anomalies in the NAC in periods with negative NAO conditions indicating a common cause for the cold anomaly over the NAC and heavy ice conditions in the Barents Sea.

The temperature response at $850 \mathrm{hPa}$ is much weaker compared to the surface and the center is not as sharply localized over the Barents Sea (Fig. 9c, f, j). The large $2 \mathrm{~m}$ air temperature anomaly in the Barents Sea is due to exchange processes at the surface. The vertical atmospheric temperature gradient within the first $1,500 \mathrm{~m}$ is reduced by 1-2 K. Hence, stability of the boundary layer is increased (decreased) during heavy (light) winter ice conditions in the Barents Sea. This agrees with results of $\mathrm{Wu}$ et al. (2004) who found a more stable winter atmosphere over sea ice than over open water.

c) $\mathrm{T} 850 \mathrm{hPa}$, lag 0

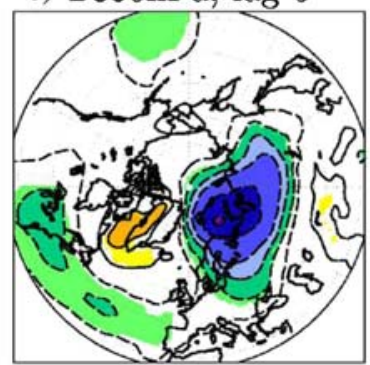

f) $\mathrm{T} 850 \mathrm{hPa}, \operatorname{lag} 1$

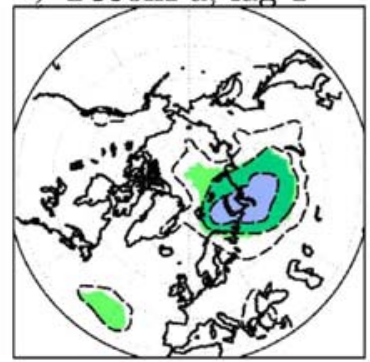

j) $\mathrm{T} 850 \mathrm{hPa}, \operatorname{lag} 2$
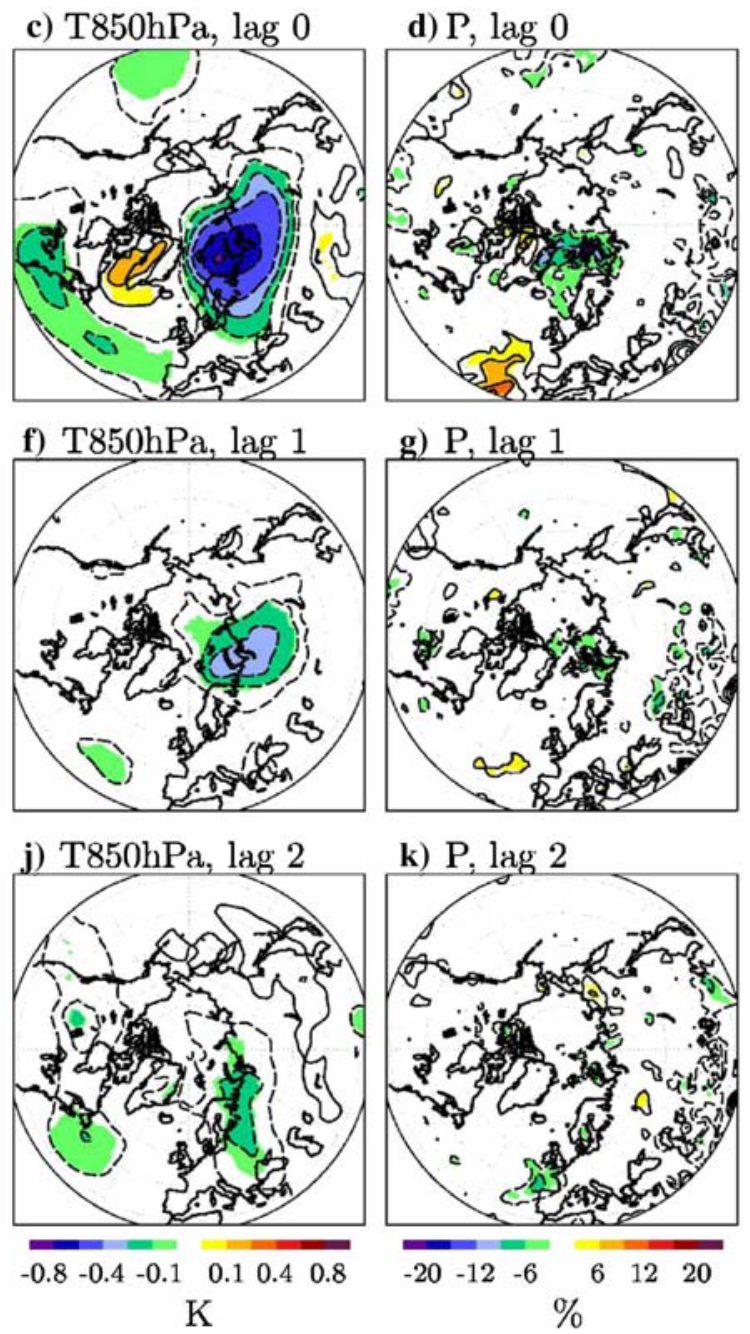

k) P, $\operatorname{lag} 2$

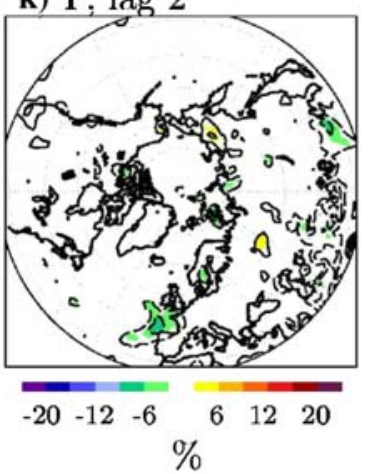

(bottom) years. Statistical significant areas at the 95\% level are displayed in color. The contour lines follow the labeling of the color palette. For albedo a smaller region is shown

Precipitation in the Nordic Seas is significantly smaller in years with large sea ice volume in the Barents Sea (Fig. 9d, g, h). In the Barents Sea itself, precipitation is reduced by up to $20 \%$. In the following 2 years, precipitation stays below normal in the Barents Sea. The reduced oceanic heat release and the more stable atmosphere lead to a decrease of convective precipitation events. Large-scale precipitation is also reduced since fewer cyclones propagate into Barents Sea during years with heavy ice conditions. Note that precipitation shows almost no response over land areas, which is in contrast to air temperature.

The effect of minimum IVB on climate (not shown) is nearly symmetric. The reduced sea ice cover and thickness lead to decreased albedo, above normal oceanic heat release, negative SLP anomaly, strongly increased temperatures and enhanced precipitation in the Barents Sea in 
years during and after the minimum. Both distribution and amplitude of the response are comparable to the large IVB case.

Anomalies of ocean surface temperature (SST, mean of $12 \mathrm{~m}$ thick uppermost grid cell in our model) and surface salinity (SSS) are subject to rather strong multi-decadal variations. Hence, we used a 11-year Hanning high-pass filter for the composite analysis of SST and SSS to extract the interannual response to the sea ice anomalies (Fig. 10). The SST pattern is characterized by large cold anomalies in the Barents Sea and in the North Atlantic and a smaller warm anomaly in the Labrador Sea during years with large IVB. The SST anomaly in the Barents Sea is due to cooling from above by enhanced sea ice and a cold atmosphere. A displacement and weakening of the North Atlantic Current (NAC) is responsible for the cooling in the North Atlantic. Anomalous advection of warm surface waters and easterly wind anomalies reduce sea ice cover in the Labrador Sea, which leads to a warming in the Labrador Sea along the ice edge. The positive anomaly in the Labrador Sea disappears rather fast while the negative anomalies stay significant for one to two years. The SST pattern is similar to that of $2 \mathrm{~m}$ air temperature (Fig. 9b, e, i) but the response is more localized and weakens faster.

Surface salinity is significantly reduced in the Barents Sea at lag 0 . Since sea ice volume is above normal, melting is intensified and salinity reduced. This negative salinity anomaly weakens in the following year and disappears at a lag of 2 years. In the Kara Sea, where sea ice volume is also above normal, a significant negative salinity anomaly occurs after 2 years. Houssais et al. (2007) forced a coupled ocean-sea ice model with winds and air temperatures of the positive AO-phase, which normally leads to slightly enhanced sea ice concentration and thickness in the Barents Sea. They did not find any strong salinity response in the Barents Sea but showed a substantial positive salinity anomaly in the Kara Sea similar to the anomaly in our simulations. Sundby and Drinkwater (2007) analyzed salinity data since 1947 and found in contrast to Houssais et al. (2007) a clear relation between the 3-year mean NAO-index and salinity north of the Kola Peninsula. Furthermore, they showed that high salinity is related to a high propagation speed of the salinity anomaly and vice versa. Furevik (2001) analyzed hydrographic sections in the
Fig. 10 Anomalies of annual mean sea surface temperature (in Kelvin) and surface salinity (in psu) during years with high Barents Sea ice volume (left), after one (middle) and after two (right) years. Significant areas at the $95 \%$ level are displayed in color. The contours show each second level a) SST, lag 0

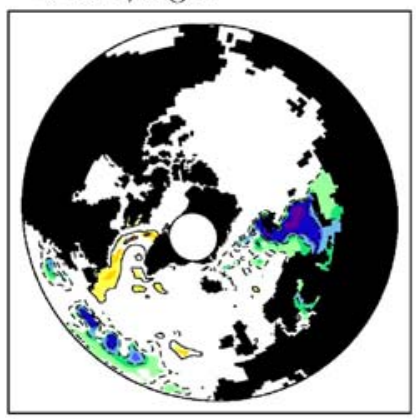

b) SST, lag 1 year

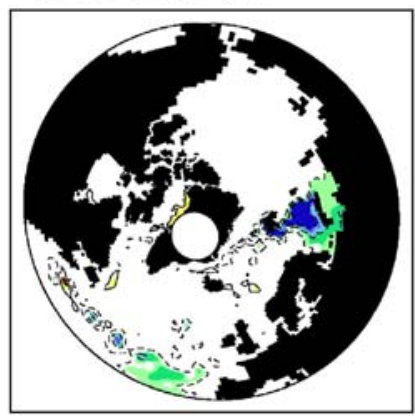

c) SST, lag 2 years
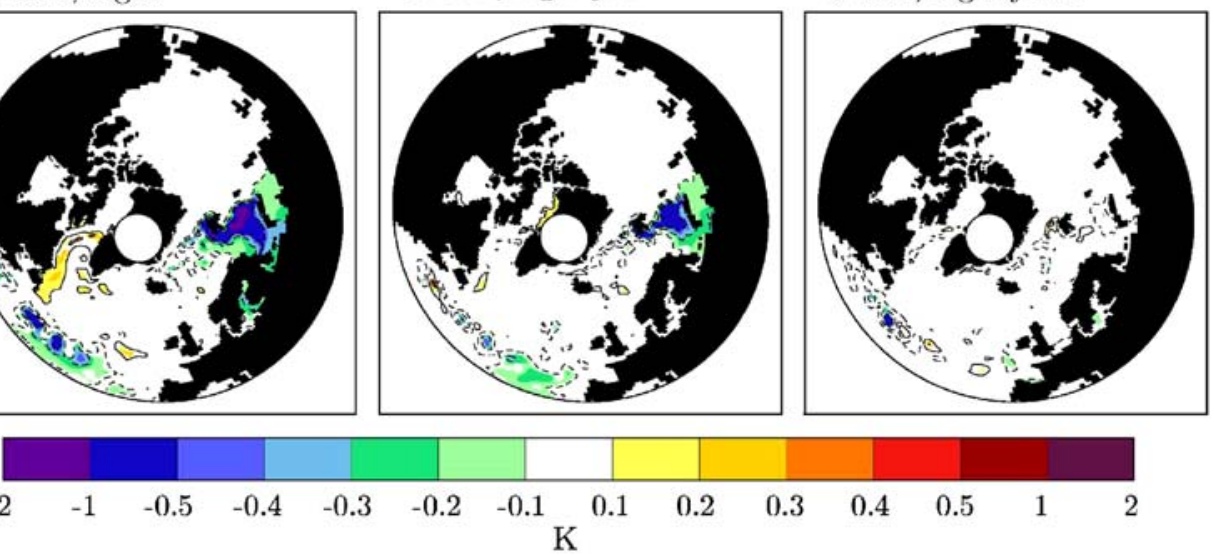

d) SSS, lag 0

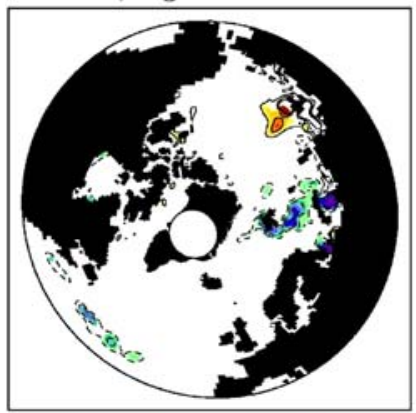

e) SSS, lag 1 year

f) $\mathrm{SSS}$, lag 2 years
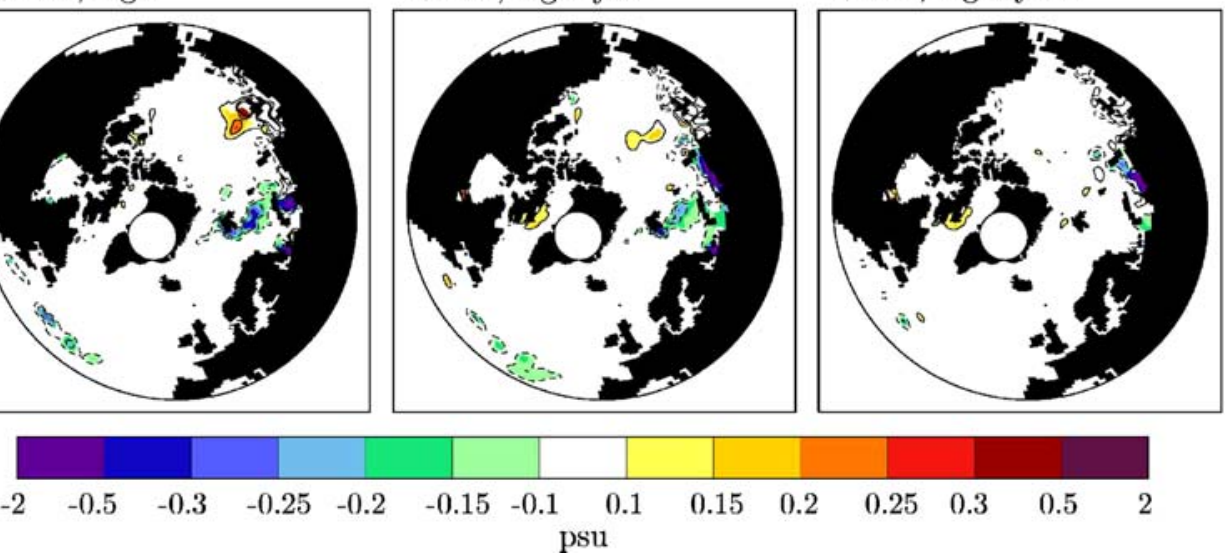
Barents Sea opening and showed that at least the temperature of the inflowing water is related to the phase of the NAO.

The weakening and displacement of the NAC reduces SSS in the NAC in our simulation. The weakening of the NAC leads to less transport of warm and salty water into this area and cold and fresh sub-polar waters penetrate further to the south. Along the Siberian coast, SSS anomalies are strong but statistically only marginally significant because salinity variations are very high at the Siberian coast due to a strong dependence of melting and freezing processes on the atmospheric circulation and variations of the river runoff.

\subsection{Seasonal climate response to sea ice anomalies in the Barents Sea}

In the following, the seasonal climate anomalies associated with anomalous IVB are discussed. Figures 11 and 12 show SLP and $2 \mathrm{~m}$ air temperature during large IVB (exceeding mean +1 standard deviation) in winter (DJF, a), spring (MAM, b), summer (JJA, c) and autumn (SON, d) and the following seasons. The season with maximum anomalous IVB (except for summer) is characterized by a SLP pattern similar to the lag 0-regression pattern of annual values. During winter, spring and autumn, pressure over the Nordic Seas is anomalously high with maximum over Svalbard and anomalously low further south over the North Atlantic. During summer, the pattern is dominated by anomalously low SLP in Kara and Laptev Sea. However, in all seasons, a rather strong (weakest in summer) SLP-gradient between Svalbard and Novaya Zemlya leads to strong sea ice transport into the Barents Sea. It is difficult to say what part of the SLP anomaly at lag 0 is a response to the ice anomaly in the Barents Sea. However, in all seasons-except for summer-the SLP anomalies are most pronounced around Spitsbergen and in the Barents Sea. This may lead to the conclusion that the atmosphere in this area reacts to the sea ice anomaly below at lag $0 . \mathrm{Wu}$ et al. (2004) used reanalysis data and performed composite analysis of SLP for light and heavy winter ice conditions in the region Greenland/Barents Sea. Similar to us, they found the strongest SLP anomaly in the area of large ice conditions and concluded that sea ice anomalies partly determine the local SLP anomalies. Independent of the season of maximum ice volume, the SLP anomalies in the following seasons are largest in winter and spring. Temperature differences between atmosphere and ocean and hence heat flux anomalies are particularly large in this time period. Main characteristics of the winter and spring pattern are positive SLP anomalies over the Barents Sea and over north and northeastern Europe. Furthermore, SLP tends to be above normal over the Arctic Ocean and below normal over the northwestern North Atlantic. A two-sided $t$ test shows that at least parts of these anomalies are significant at the $95 \%$ level. The anomalous autumn SLP pattern is similar but with a smaller amplitude. The center of the positive response over the Barents Sea moves with the ice edge towards Kara Sea. In autumn after maximum IVB in spring, no significant values at all can be seen in mid and high northern latitudes. The smallest anomalies occur during summertime, when the differences between ocean and atmosphere temperature and hence heat fluxes are small. Changes in ice cover and thickness have therefore only a small impact on the atmospheric circulation in autumn. The anomalies in the second year after maximum IVB are generally small.

The SLP response after low IVB is almost symmetric to the response to large IVB. SLP is significantly reduced in the Barents Sea and surroundings (not shown) and again, the response is smallest in summer.

The $2 \mathrm{~m}$ air temperature shows a strong cooling of more than $2 \mathrm{~K}$ centered over the Barents Sea in all seasons with large positive IVB. This negative anomaly spreads out laterally and is significant over the entire northern and northeastern Europe and over western and middle Siberia. During summer, the anomaly has a slightly reduced extension. In the seasons after high IVB, air temperature stays much colder than normal in the Barents Sea mainly due to the strongly reduced ocean heat release. The anomaly reaches up to $4 \mathrm{~K}$ in winter, spring and autumn but stay below $2 \mathrm{~K}$ in summer. The cold temperatures extend to northern Russia, Kara Sea, Laptev Sea and the European Central Arctic in winter and spring. In autumn, the anomaly extends mainly eastward along the Siberian coast. The cold air is advected with the mean atmospheric circulation to the north and east. In summer, the cold region is more limited in its extension. After seasons with low IVB, the anomaly patterns of air temperature are almost symmetric and show much warmer temperatures than normal.

Bengtsson et al. (2004) performed simulations with an AGCM forced with the Global Sea Ice and Sea Surface Temperature Data Set (GISST) for the twentieth century. They used a discontinuity in the sea ice data set leading to a mean reduction of the sea ice area by $2 \times 10^{6} \mathrm{~km}^{2}$ after 1949 to analyze the atmospheric response. This leads to a decreased sea ice concentration by $5-40 \%$ in the Barents Sea. Although not only sea ice in the Barents Sea was decreased, the local response in the Barents Sea was similar to our results from the control integration. The reduced sea ice concentration in Bengtsson et al. led to an increased winter ocean heat release by up to $150 \mathrm{~W} / \mathrm{m}^{2}$. The temperature increased by 6 and more Kelvin and SLP responded with a local reduction of about $1.5 \mathrm{hPa}$. The response is about $50 \%$ higher than in our composite 


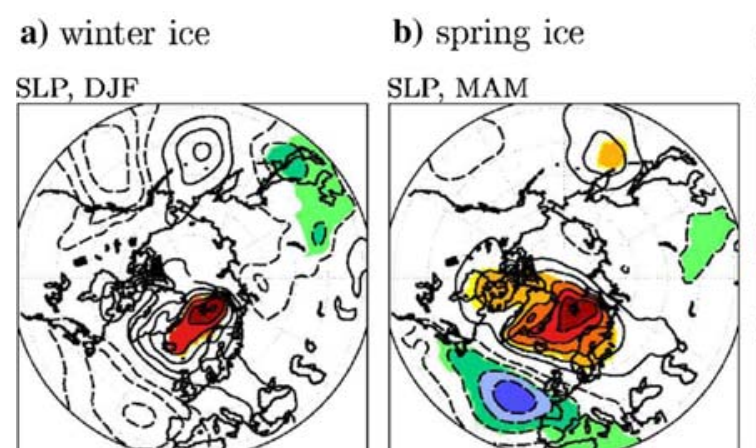

SLP, JJA

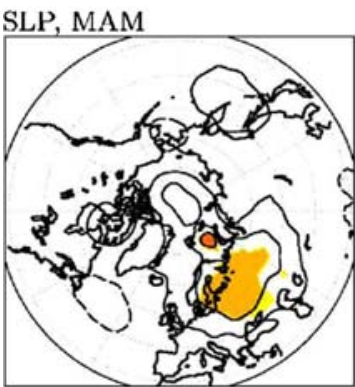

SLP, JJA

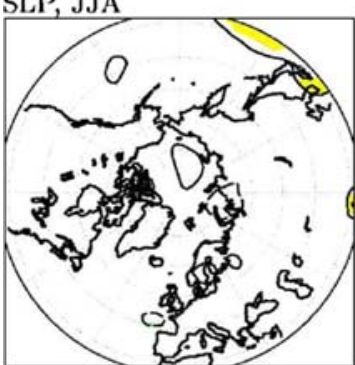

$-2.0 \quad-1.5 \quad-1.2$

$-0.9$

$-0$.

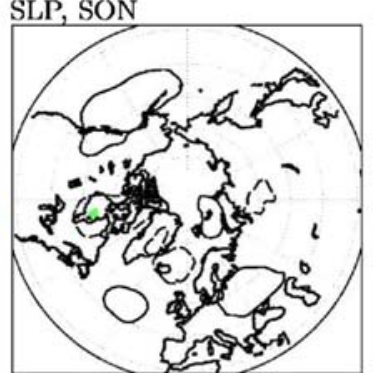

Fig. 11 Anomalous seasonal mean SLP anomalies (in hPa) during large positive winter (a), spring (b), summer (c) and autumn (d) ice volume anomalies in the Barents Sea and in the two following

analysis. However, this can mainly be explained by a stronger sea ice reduction in the Barents Sea in their study.

Rinke et al. (2006) analyzed the impact of lowerboundary forcing on the mean state of the atmosphere by forcing a regional atmosphere model with two different sets of sea ice and SST. They found that local air temperature is colder (warmer) and SLP higher (lower) where sea ice concentration is increased (reduced). The effect is most pronounced along the displaced ice edge and much weaker in the Arctic's interior. Moreover, their results show a strong annual cycle of the air temperature differences with large changes in winter and small changes in summer. This agrees well with our findings for the Barents Sea. Interestingly, SLP anomalies do not show an annual cycle in their simulation, which is in contrast to our results. Keup-Thiel et al. (2006) analyzed the future climate c) summer ice

SLP, JJA

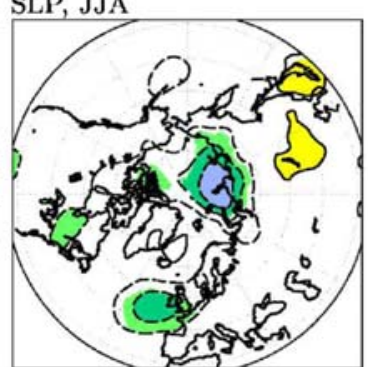

d) autumn ice

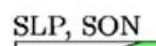
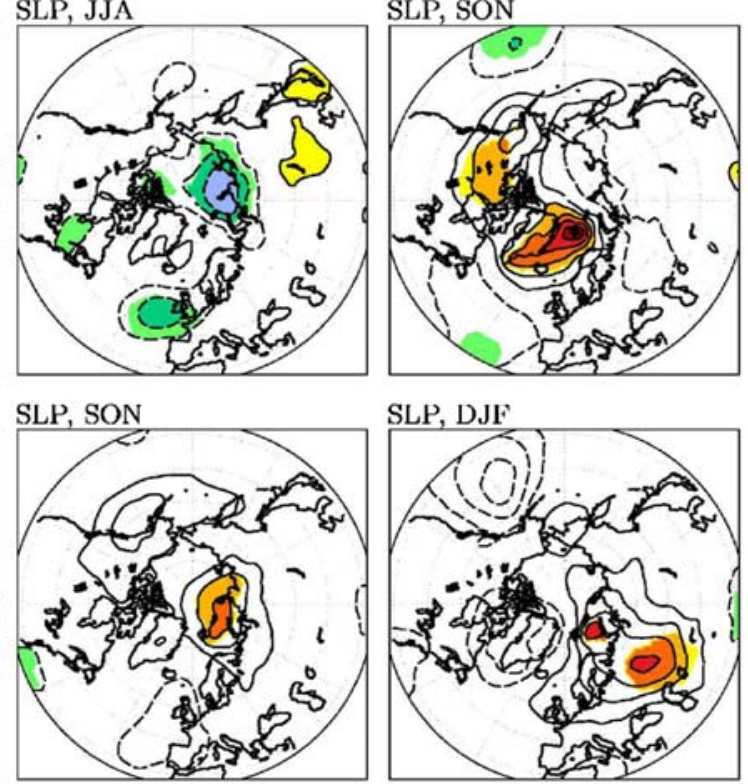

SLP, DJF

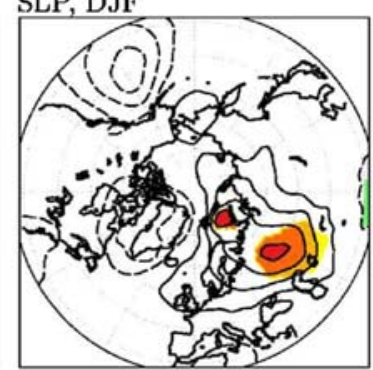

SLP, DJF

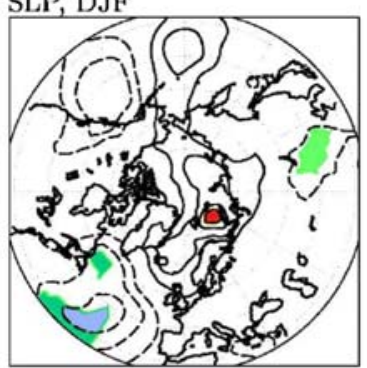

SLP, MAM
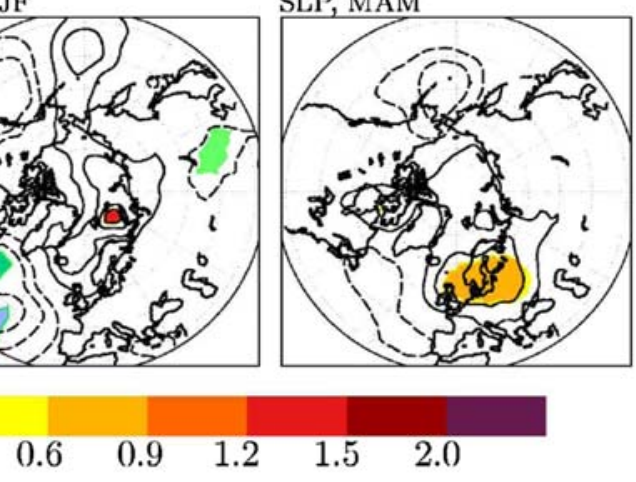

seasons. Significant areas at the $95 \%$ level are displayed in color. The contour lines follow the labeling of the color palette

development in the Barents Sea region with a regional atmosphere model. The anomaly patterns of summer and winter air temperature for the time slice 2011-2030 in their simulations compare well with the response to negative IVB in our control integration (not shown).

As noted above, it is difficult to separate between the effect of anomalous sea ice anomalies in the Barents Sea and the response to the forcing leading to this sea ice anomaly in a lag 0 regression or composite analyses of the control integration. Since NAO influences IVB, we subtract the NAO-signal from the lag 0 composite in the following. We determine the NAO-index during high and low (exceeding mean \pm 1 standard deviation) IVB and calculate the SLP and $2 \mathrm{~m}$ air temperature pattern belonging to these NAO-indexes. The pattern gained by this simple procedure is subtracted from the lag 0 pattern during high 
a) winter ice
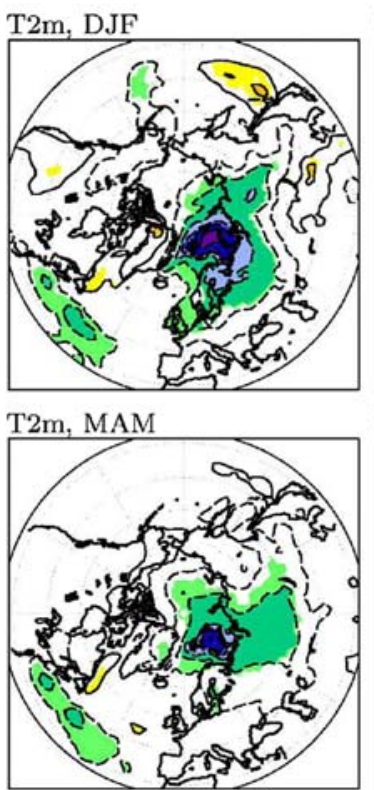

T2m, J.JA
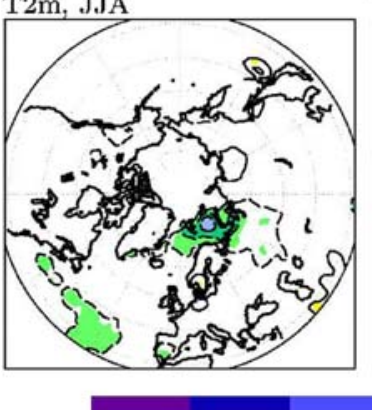

b) spring ice
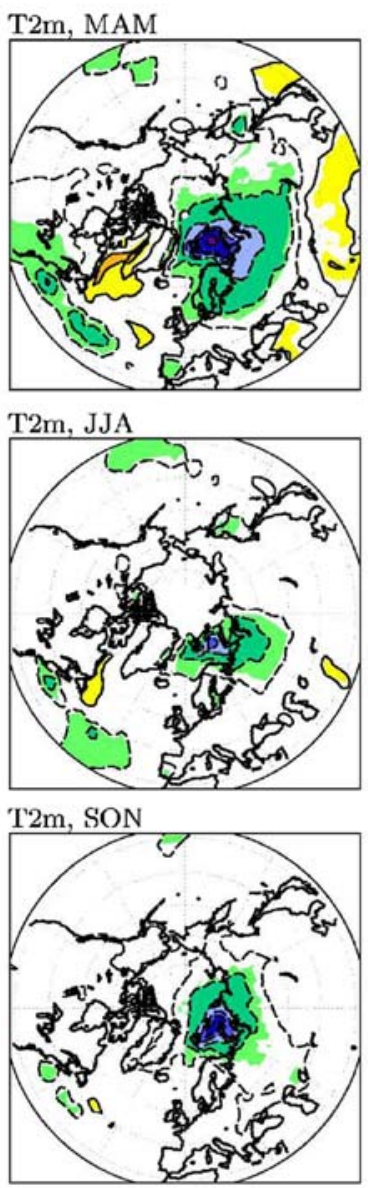

$-4.0 \quad-2.0 \quad-1.5 \quad-1.0 \quad-0.5 \quad-0.2$ c) summer ice
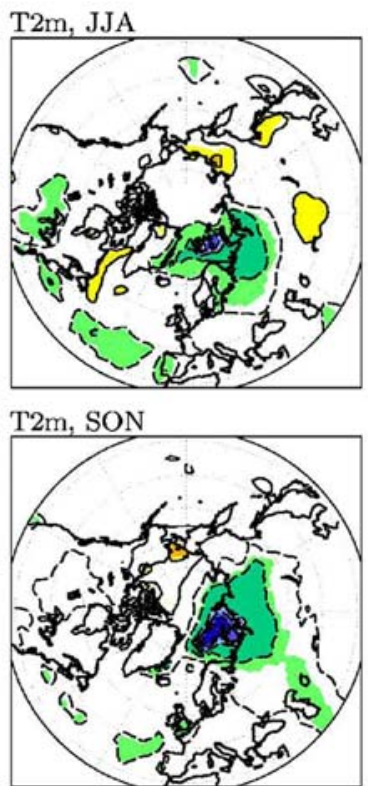

T2m, DJF

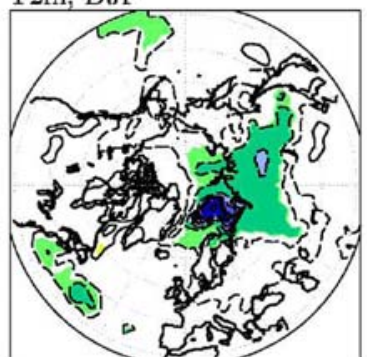

$-3$ d) autumn ice
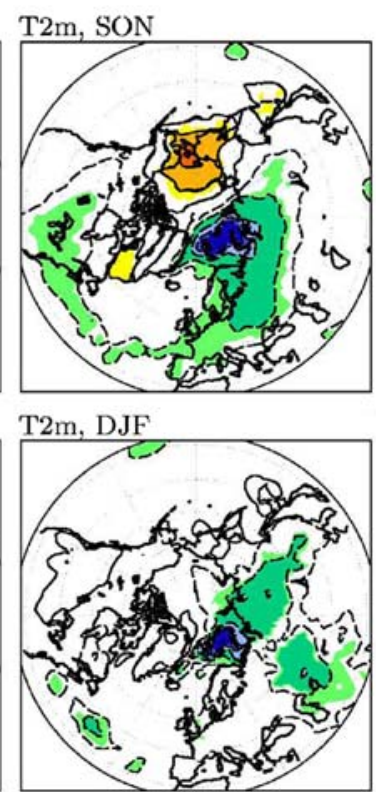

T2m, MAM

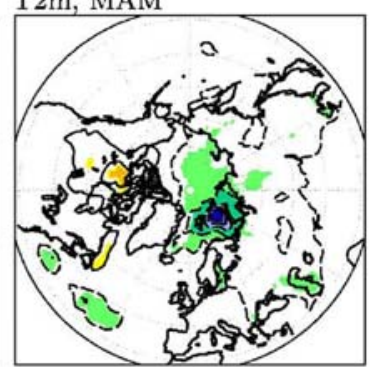

$\begin{array}{llllll}0.2 & 0.5 & 1.0 & 1.5 & 2.0 & 4.0\end{array}$
Fig. 12 Anomalous seasonal mean $2 \mathrm{~m}$ air temperature (in Kelvin) during large positive winter (a), spring (b), summer (c) and autumn (d) ice volume anomalies in the Barents Sea and in the two following

and low IVB (Fig. 13). The by far largest SLP anomalies occur in the Barents Sea itself and the negative anomaly over the North Atlantic has almost disappeared. The air temperature pattern at lag 0 is now very similar to the lag 1 pattern and does not show the dipole over the Labrador Sea anymore. However, these patterns still include the nonNAO forcing, which is responsible for the formation of sea ice volume anomalies in the Barents Sea. Therefore, additional sensitivity studies are necessary to isolate the response of atmospheric climate conditions to sea ice variations in the Barents Sea.

\section{Sensitivity experiments}

Sensitivity experiments with the coupled atmosphereocean GCM ECHAM5/MPI-OM are performed to isolate seasons. Significant areas at the $95 \%$ level are displayed in color. The contour lines follow the labeling of the color palette a) SLP

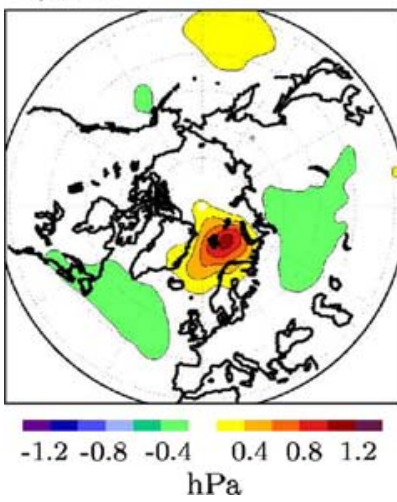

b) $\mathrm{T} 2 \mathrm{~m}$

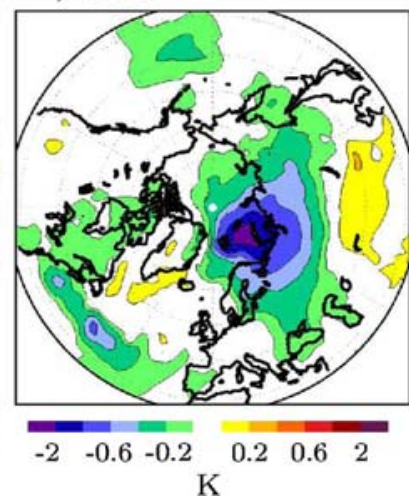

Fig. 13 Anomalies of non-NAO annual mean SLP (a, in hPa) and $2 \mathrm{~m}$ air temperature (b, in Kelvin) during high Barents Sea ice volume. From the composite patterns of SLP and $2 \mathrm{~m}$ air temperature, the NAO contribution is subtracted 
the climate response to large sea ice anomalies in the Barents Sea. Twenty experiment runs starting at 1 January with initial conditions from 31 December of 20 different years of the control integration are performed. In each run, the initial conditions of sea ice concentration and sea ice thickness in the Barents Sea are replaced by the ice conditions of May 602 from the control integration, which is the month with largest ice volume in the Barents Sea. The ice volume in the Barents Sea is increased from an average of the control integration of $0.33 \times 10^{12}$ at 31 December to $1.0 \times 10^{12} \mathrm{~m}^{3}$ in the experiment runs. This means that the mean ice thickness of the Barents Sea is increased by about $0.45 \mathrm{~m}$ in the initial conditions. The ice cover is increased from $0.44 \times 10^{12}$ to $0.99 \times 10^{12} \mathrm{~m}^{2}$. In order to allow coupled feedbacks in the model, sea ice can freely develop after reinitialization. We do not change any other variables in the initial conditions to really obtain the response to the sea ice anomaly in the Barents Sea. This may cause a slightly faster melting of the sea ice anomaly in our experiments than in the model's control integration since initial conditions of ocean temperatures in the Barents Sea are warmer in the experiments than in years with high Barents Sea ice volume. However, this melting effect is of minor importance for our results since we only analyze the climate response in the first year after initialization. In the following, we compare the mean of the 20 experiment runs with the mean of the corresponding 20 periods of the control integration.

Sea ice concentration and thickness in the first year after reinitialization are strongly enhanced in the experiments compared to the mean of the corresponding individual years of the control integration (Fig. 14). Sea ice concentration is increased by $30-60 \%$ in most of the northern and eastern Barents Sea. A significant above normal sea ice a) ice concentration

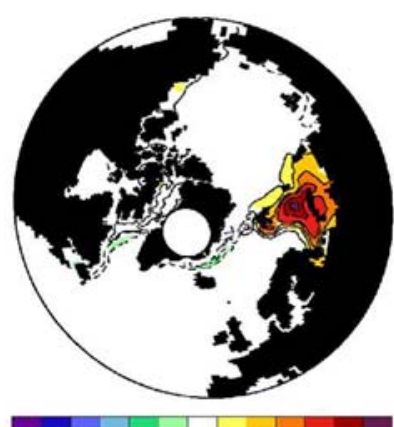

$\begin{array}{llllll}-0.6 & -0.3 & -0.1 & 0.1 & 0.3 & 0.6\end{array}$ parts

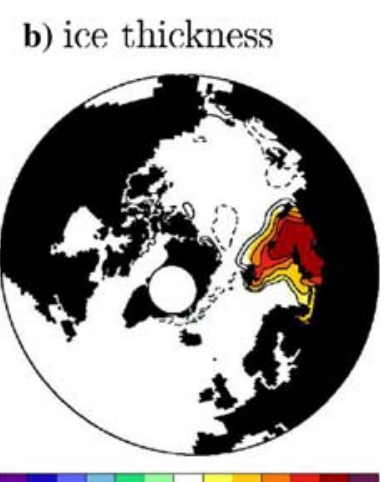

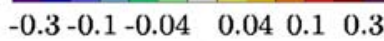
$\mathrm{m}$
Fig. 14 Response of annual mean sea ice concentration (in parts, left) and sea ice thickness (in $\mathrm{m}, r i g h t$ ) in the first year after reinitialization. Ensemble means are shown. Significant areas at the $95 \%$ level are displayed in color. The contour lines follow the labeling of the color palette concentration occurs also in the Kara Sea. Obviously, heavy ice conditions in the Barents Sea lead to reduced sea ice melting in summer and increased ice formation in winter in the Kara Sea. Additionally, parts of the ice anomaly in the Barents Sea may be advected into the Kara Sea. Ice thickness anomalies are largest in the northeastern Barents Sea and the Kara Sea ranging from 0.2 to $0.3 \mathrm{~m}$. Further to the southwest, anomalies are smaller but the standard deviation of ice thickness is also rather small in this area. Ice thickness is slightly reduced-although not significantly-in the Laptev/East Siberian Seas and in the East Greenland Current. These ice anomalies can mainly be explained by anomalies of the atmospheric circulation.

SLP is above normal in most of the Arctic and has two centers with particularly high pressure in the first year after reinitialization (Fig. 15a). One is localized in the Barents Sea itself and is due to the reduction of the heat fluxes from ocean to atmosphere. This positive SLP anomaly leads to a slightly reduced SLP-gradient across Fram Strait and reduces Fram Strait sea ice export and hence sea ice thickness in the East Greenland Current. The second center is situated over the East Siberian and North American Arctic and leads to offshore winds at the Siberian coast and reduces sea ice thickness there. However, these anomalies are not significant at the $95 \%$ significance level. A significant positive SLP anomaly occurs over Newfoundland and a rather strong negative anomaly over Scandinavia.

The SLP response in the experiment differs from the regression between SLP and IVB in the control run, which only shows above normal SLP in the Barents Sea. Two things have to be noted: First, the SLP response is rather small in both the control integration and the experiment. Second, the experiment shows the response to an isolated sea ice anomaly in the Barents Sea while this is not the case in the control integration. Magnusdottir et al. (2004) and Deser et al. (2004) analyzed the atmospheric response to prescribed sea ice anomalies in Barents, Greenland and Labrador Seas in an AGCM. They divided the response into a direct and indirect part. While the direct response leads to high pressure over positive sea ice anomalies, changes in the baroclinity due to sea ice induced temperature anomalies govern the indirect part. In our experiment, the cooling in the Barents Sea (Fig. 15b) increases the meridional temperature gradient and hence baroclinity, which may explain the negative SLP anomaly over Scandinavia.

The strong cooling in the Barents Sea in the experiments is similar to the composite pattern of temperature in the control integration (Fig. 9e). In the experiments, this anomaly extends further south to Scandinavia but not as far to the south to Siberia. Furthermore, the sensitivity experiment does not reproduce the negative anomaly over the NAC in the northwestern North Atlantic. This 
a) SLP
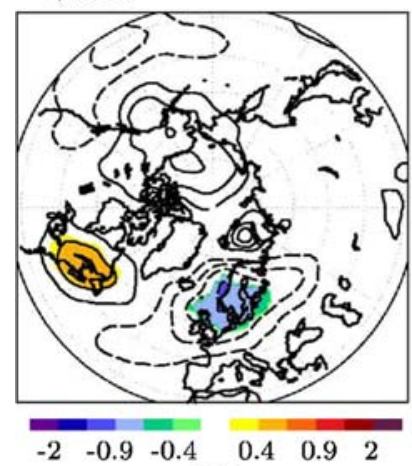
$\mathrm{hPa}$

c) Prec

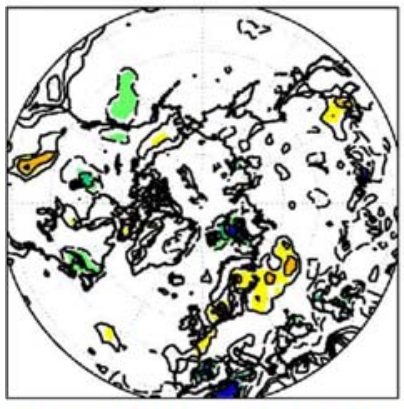

$-30-16-8$ b) $\mathrm{T} 2 \mathrm{~m}$

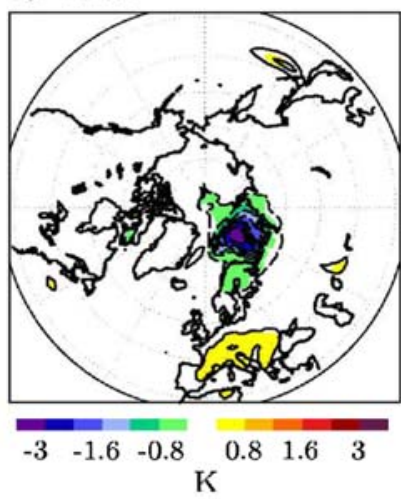

d) $\mathrm{T} 850 \mathrm{hPa}$

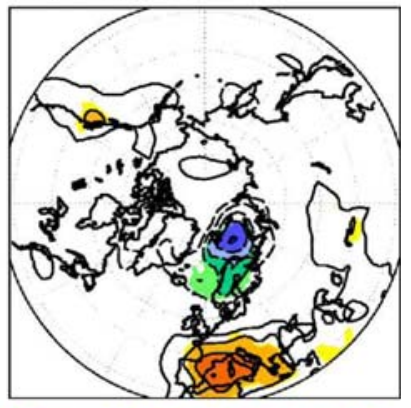

$\begin{array}{llllll}-0.8 & -0.5 & -0.3 & 0.3 & 0.5 & 0.8\end{array}$

Fig. 15 Response of annual mean SLP (a, in hPa), $2 \mathrm{~m}$ air temperature (b, in Kelvin), precipitation (c, in \% relative to the annual mean) and $850 \mathrm{hPa}$ air temperature (d, in Kelvin) in the first year after reinitialization. Ensemble means are shown. Significant areas at the $95 \%$ level are displayed in color. The contour lines follow the labeling of the color palette

strengthens our suggestion from the analysis of the control integration that this anomaly is produced by the processes taking place during the formation of the IVB-anomalies. It is not directly related to physical processes in the Barents Sea.

From northern Spain across the Alps to the Black Sea, temperatures are significantly higher in the experiment. This warming is caused by the anomalous south-westerlies at the southern side of the negative SLP anomaly over Scandinavia.

Precipitation is strongly reduced over the Barents Sea in the first year after reinitialization (Fig. 15c). This reduction is limited to the area with increased initial sea ice cover and thickness. Interestingly, precipitation in the Kara Sea is not decreased although sea ice conditions are heavy in the first year as well. Over northeastern Europe precipitation is significantly increased by up to $15 \%$. This anomaly is again related to the negative SLP anomaly over Scandinavia and the anomalous transport of warmer and more moist air masses from the North Atlantic. Smaller regions with a

significant response can also be seen over North America and the southwestern Mediterranean.

The response of temperature in $850 \mathrm{hPa}$ height shows a similar pattern than the $2 \mathrm{~m}$ air temperature (Fig. 15d). The most pronounced anomaly occurs over the Barents Sea with a cooling of up to $1 \mathrm{~K}$. Hence, the amplitude of this negative anomaly is much smaller than at the surface. This leads to a reduced vertical temperature gradient in the Barents Sea during heavy ice conditions and a stabilization of the lower troposphere. The strong reduction in the ocean heat release mainly influences near surface temperatures. In contrast to the Barents Sea, the anomaly over southern Europe has the same amplitude in $850 \mathrm{hPa}$ and at the surface. This anomaly is produced by anomalous advection of warm air masses from the North Atlantic, which is rather independent of the height. Similar to the $2 \mathrm{~m}$ air temperature, the $850 \mathrm{hPa}$ temperature anomaly over the Barents Sea extends further to the south over Scandinavia but not as far into Siberia compared to the control integration.

To further analyze the vertical structure of the lower troposphere over the Barents Sea, we investigated air temperature and geopotential height anomalies in a vertical section at $78^{\circ} \mathrm{N}$ (Fig. 16). Since the response is small and not significant above $700 \mathrm{hPa}$, we only show the lower
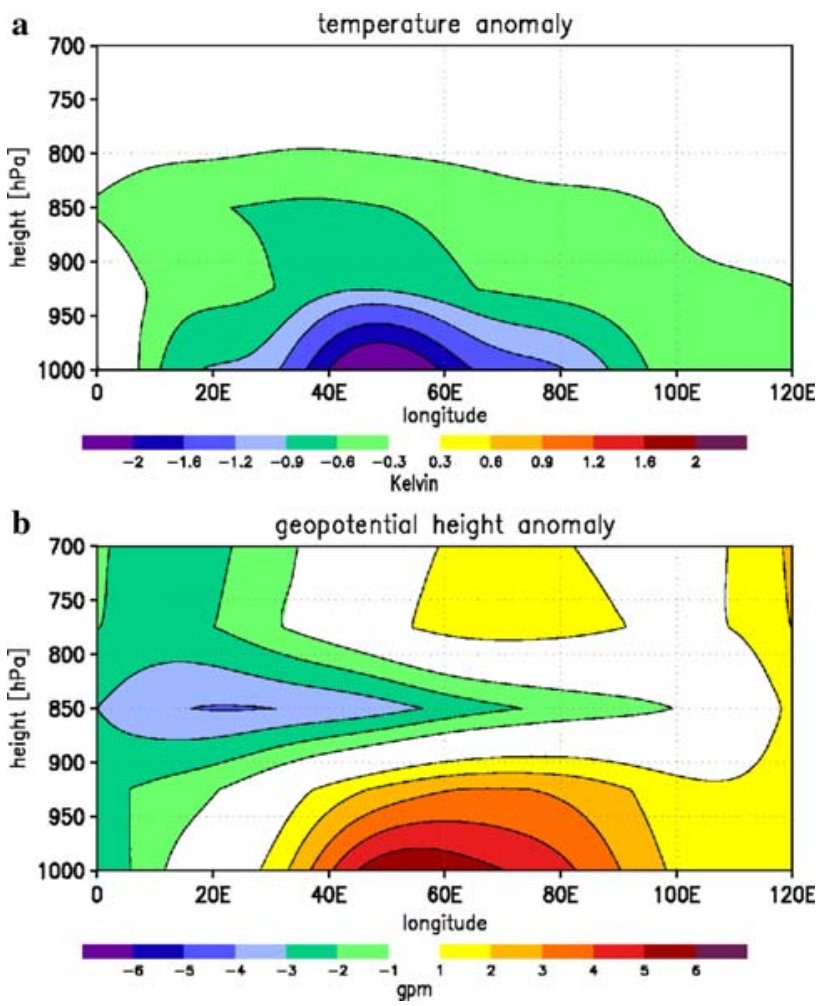

Fig. 16 Response of the vertical structure of annual mean air temperature (a, in Kelvin) and geopotential height (b, in gpm) along a section at $78^{\circ} \mathrm{N}$ from 0 to $120^{\circ} \mathrm{E}$. Ensemble means are shown 
troposphere below $700 \mathrm{hPa}$. The ensemble mean response of annual mean temperature is largest near the surface in the eastern Barents Sea between $40^{\circ} \mathrm{E}$ and $60^{\circ} \mathrm{E}$. The anomalies are strongly reduced with increasing height and totally disappear at $800 \mathrm{hPa}$ height at these longitudes. West of $20^{\circ} \mathrm{E}$ and east of $90^{\circ} \mathrm{E}$, temperature anomalies are generally small. Consistent with the cold temperature anomalies, the geopotential height field shows positive height anomalies over the Barents Sea in the lowermost 50-100 hPa. Also the response of the geopotential height strongly decreases with height and disappears or becomes even negative above $900 \mathrm{hPa}$. Obviously, the anomalously strong cooling from the surface of the Barents Sea produces a cold high pressure system. Those pressure systems are characterized by their small vertical extension. The vertical structure of the geopotential height clearly indicates a baroclinic response to the ice anomalies. Singarayer et al. (2006) forced an AGCM with predicted sea ice changes in the twenty-first century. They found a wintertime warming of up to $20 \mathrm{~K}$ winter in the northern Barents Sea while the mean Arctic warming was only $3.9 \mathrm{~K}$. They analyzed the vertical structure of this temperature and showed a similar strong reduction of the signal with height.

The seasonal response of sea ice thickness, SLP and $2 \mathrm{~m}$ air temperature in the first year after the start of the experiment is shown in Fig. 17. In the first 2 months (January, February), the ice anomaly is largest in the Barents Sea since the anomaly has been added there. However, sea ice is already thicker as usual in most parts of the Kara Sea. In the following months, the ice anomaly is reduced in the Barents Sea but further develops in the Kara Sea. In autumn, ice thickness anomalies become smaller in Barents Sea and Kara Sea.

SLP is increased in the entire Arctic region in the first 2 months. Large areas of the Arctic are significant at the 90\% level but only the Barents Sea and parts of the Canadian Archipelago are significant at the 95\% level. The SLP anomaly reaches 2-4 hPa over the Arctic Ocean and up to $5 \mathrm{hPa}$ in the Barents Sea. Further south, SLP is generally below normal, which leads to a kind of annular structure. The strongest negative anomaly occurs over the North Pacific with $-3 \mathrm{hPa}$ but is only partly significant. Although similarities to the winter SLP composite pattern of the control integration can be seen, the annular structure is not that dominant in the control run. One important reason for this might be that high ice volume in the Barents Sea goes along with below normal sea ice volume in the Labrador Sea in the control run. These ice anomalies are important for the large-scale atmospheric circulation (Koenigk et al. 2006; Kvamstö et al. 2004) and count at least for a part of the differences between control run and experiment. In spring, SLP anomalies are still positive but predominantly not significant over the Arctic Ocean and negative over the North Atlantic, northern Europe and the North Pacific. The distribution changes towards summer, when SLP is below normal in most Arctic regions. This shift in the anomalies can also be seen in the control run although differences occur in detail. In autumn, SLP anomalies stay negative in the Nordic Seas and the European Arctic, which contradicts the analysis from the control integration. Furthermore, the results from the sensitivity experiment show positive SLP anomalies from the northeastern Pacific across Canada and the North Atlantic towards Spain.

Air temperature is colder than usual in the entire Arctic region in the first 2 months of the experiment. This fits well to the higher SLP in the Arctic, which reduces atmospheric heat transports into the Arctic and enhances terrestrial radiation. In the control run, there are no or only small negative temperature anomalies at the North American Arctic coast. This is not surprising because sea ice there is reduced during high IVB. The cooling in the Barents Sea reaches almost $10 \mathrm{~K}$ in the experiment, which is much more than in the control run. However, comparing to the $20 \mathrm{~K}$ warming in the Barents Sea in the twenty-first century found by Singarayer et al. (2006) this does not seem to be an unrealistic value. In spring, still most of the Arctic shows negative air temperature anomalies. In the Barents Sea, temperature is reduced by about $4 \mathrm{~K}$. A slight warming can be seen over southern Europe, which is related to advection of warm air masses due to negative SLP anomalies. Although the amplitude of the response is smallest in summer, the area with a statistical significant temperature response is particularly large. Air temperature in the Barents Sea and entire Scandinavia is significantly reduced while it is increased in southwestern Europe, northeastern Canada and south of Kamchatka Peninsula. In autumn, the center of the negative anomaly is slightly shifted from the Barents to the Kara Sea in accordance with the sea ice anomaly. The negative SLP anomaly over the Nordic Seas advects cold air to Greenland and Labrador Sea and warm air masses at its southern side towards middle and northeastern Europe and Siberia. Most of the differences in air temperature between the experiment and the composite analyses of the control integration are associated with differences in the atmospheric circulation. Generally, the local climate response in the Barents Sea is similar in experiment and composite analyses but largescale responses differ.

\section{Summary and conclusions}

Sea ice variability in the Barents Sea and its impact on climate variations at seasonal to interannual time scales in the AOGCM ECHAM5/MPI-OM are investigated. A 465- 
a) JF

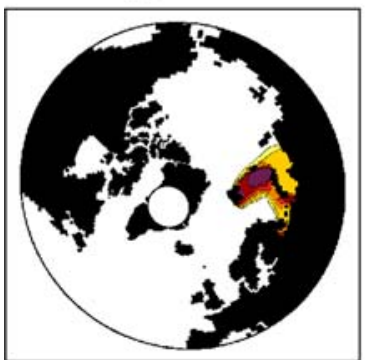

b) MAM

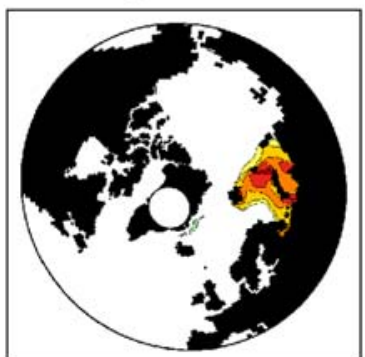

c) JJA

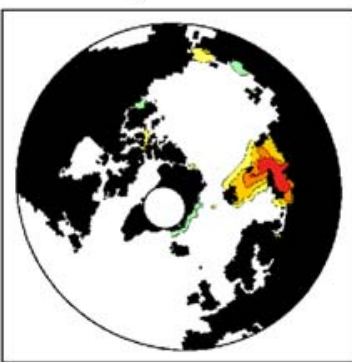

d) $\mathrm{SON}$

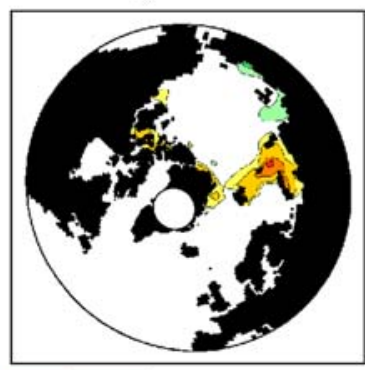

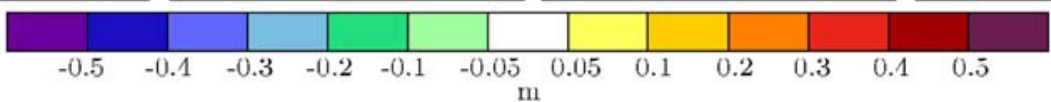

e) $\mathrm{JF}$
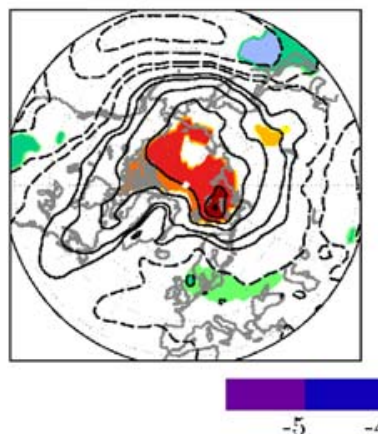

$-5$

SLP

f) MAM

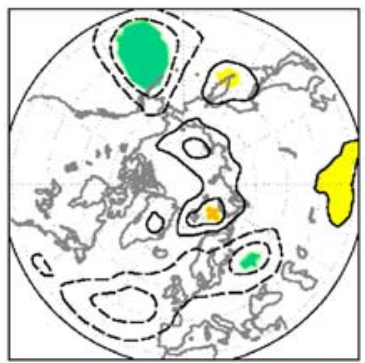

i) $\mathrm{JF}$

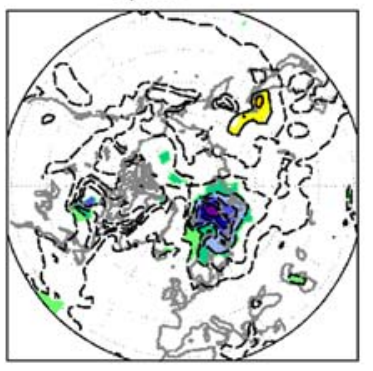

$\begin{array}{llllll}-8 & -3 & -1.2 & 1.2 & 3 & 8\end{array}$
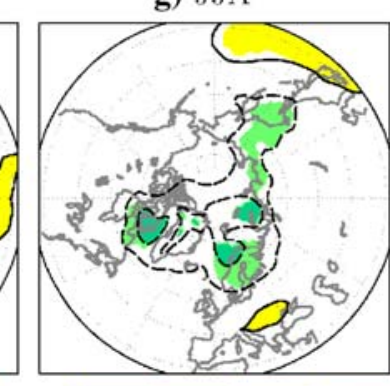

g) $\mathrm{JJA}$

h) $\mathrm{SON}$

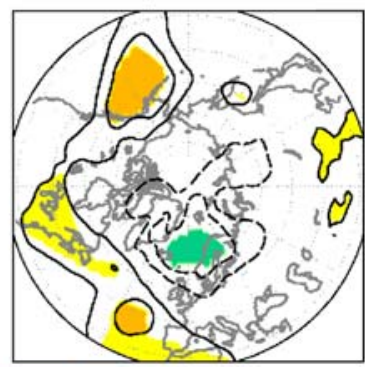

0.5

T2m

k) $\mathrm{JJA}$
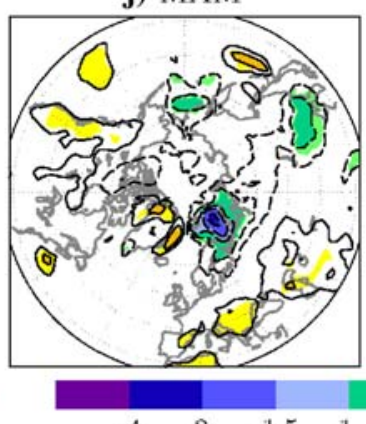
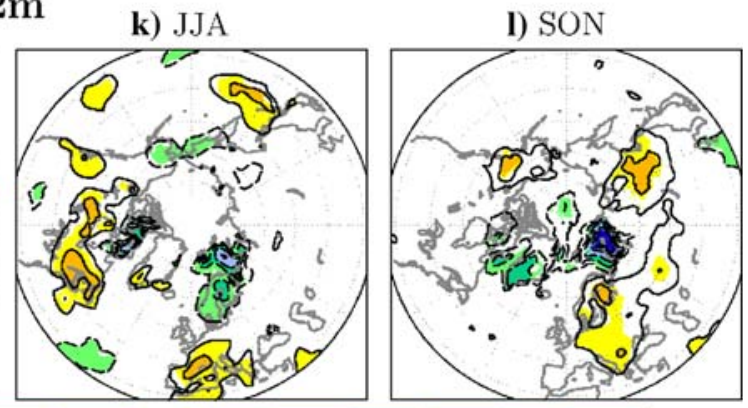

$-0.6-0.3$ K

0.3

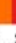

$1.5 \quad 2 \quad 4$

means are shown. Significant areas at the $90 \%$ level are displayed in color. The contour lines follow the labeling of the color palette

Fig. 17 Response of seasonal mean sea ice thickness (top, in m), SLP (middle, in $\mathrm{hPa}$ ) and $2 \mathrm{~m}$ air temperature (bottom, in $\mathrm{K}$ ) in JF, MAM, JJA, SON in the first year after reinitialization at 1 January. Ensemble

year control integration shows that the annual mean sea ice volume in the Barents Sea is highly variable at interannual to decadal time scales. The interannual variability of sea ice volume in the Barents Sea depends mainly on variations of sea ice transport from the Central Arctic into the Barents Sea. This transport is governed by local winds. Anomalously high pressure over Novaya Zemlya and below normal SLP over Svalbard strengthens the winds across the northern border of the Barents Sea and thus the sea ice transport into the Barents Sea. Negative NAO conditions lead to a slightly enhanced SLP gradient between Svalbard and Novaya Zemlya and enhanced ice transports. Interestingly, sea ice melting in the Barents Sea is particularly large in years with high ice transport into the Barents Sea and high ice volume. In those years, there is more sea ice that can be melted than in years with low ice volume. The oceanic heat transport into the Barents Sea plays therefore only a minor role for year-to-year changes. However, a cross spectrum analysis of the Barents Sea ice volume and ocean heat transport into the Barents Sea clearly shows that the ocean heat transport becomes important at longer time scales. 
Particularly large ice volume events in the Barents Sea are normally preceded by 2-3 years of sea ice accumulation. This process is related to a NAO-like SLP pattern, which leads to sea ice transports from the North American and East Siberian coasts across the Arctic towards Barents Sea. Hence, heavy sea ice conditions in the Barents Sea go along with less sea ice at the opposite side of the Arctic Ocean. After a large ice volume event in the Barents Sea, ice volume in the Barents Sea stays above normal for about two years. Composite analyses show that this leads to an albedo increase of up to $20 \%$ in the control integration. Furthermore, ocean heat release in the Barents Sea is reduced by $20 \mathrm{~W} / \mathrm{m}^{2}$ in the annual mean and by $100 \mathrm{~W} / \mathrm{m}^{2}$ in winter. Both the reduced heat fluxes and the reduced absorption of short wave radiation lead to a strong cooling in the Barents Sea. The $2 \mathrm{~m}$ air temperature is significantly reduced for two years and the anomaly extends far to Siberia, the European Arctic Ocean and parts of northern Europe. The cooling is largest in the lower troposphere, which leads to enhanced vertical stability in the atmosphere. Consequently, SLP increases in the Barents Sea and vicinity during and after high ice volume conditions. Increased vertical stability and enhanced SLP lead to significantly reduced precipitation in the Barents Sea.

Since sea ice melting in the Barents Sea is above normal in years with high sea ice volume surface salinity is significantly decreased. The seasonal anomalies of air temperature and SLP are similar in all seasons except for summer. Amplitudes are by far smallest during summer and the sign of the summer SLP response is opposite to that of the other seasons. After weak ice conditions in the Barents Sea, the climate response is nearly symmetric.

Results from additional sensitivity experiments with isolated heavy sea ice conditions in the Barents Sea confirm the results of the control integration for the local climate response in the Barents Sea. Analyses of the vertical structure of the lower troposphere show a baroclinic response of the atmosphere to the ice anomalies and the formation of a cold high pressure system. In contrast to the control integration, a negative SLP anomaly over northern Europe occurs in the experiments, which leads to significant responses of air temperature and precipitation in different parts of Europe. One explanation could be that cyclones from the North Atlantic do not propagate any longer into the Barents Sea but are blocked due to the stronger sea ice anomaly in the experiment and enter Scandinavia instead. It could also be possible that baroclinic instability due to the stronger meridional temperature gradient leads to enhanced cyclonic activity.

Alexander et al. (2004) analyzed the atmospheric response to sea ice anomalies of the winters 1983 and 1996 in an AGCM during winter. Sea ice in the Barents Sea was substantially reduced in the winters 1983 and 1996.
Although the results are not directly comparable because we analyzed the response to isolated anomalies in the Barents Sea, some local responses in the Barents Sea compare well. Alexander et al. showed strongly enhanced heat fluxes by more than $150 \mathrm{~W} / \mathrm{m}^{2}$ in the Barents Sea, which are connected with a warming of $2.5 \mathrm{~K}$ during winter. This compares to heat flux anomalies of about $100 \mathrm{~W} / \mathrm{m}^{2}$ and a cooling of $4 \mathrm{~K}$ (up to $8 \mathrm{~K}$ in the experiments) in winter in our simulations. One explanation for the higher sensitivity in our simulations could be that coupled ocean-atmosphere-sea ice feedbacks lead to an amplification of the response. The local SLP response over Barents Sea behaves differently in our two studies. We show a positive response to positive sea ice anomalies, and Alexander et al. a positive response to negative sea ice anomalies. They argue that this SLP in the Barents Sea is governed by large-scale SLP changes due to ice anomalies in other Arctic regions.

Magnusdottir et al. (2004) forced an AGCM with observed spatial sea ice anomalies in Labrador, Greenland and Barents Seas but with increased amplitude. Similar to Alexander et al. (2004) they found a negative NAO-pattern as response to negative sea ice anomalies in Greenland and Barents Sea at the same time. In contrast, Bengtsson et al. (2004) found in accordance to our result a reduction of SLP over the Barents Sea for reduced sea ice. These different results concerning the response of the atmospheric circulation can lead to different conclusions. Either the large-scale response is mainly a response to sea ice anomalies in the Greenland Sea and not to the Barents Sea or simulations with different models lead to different results.

Our conclusion that the Barents Sea plays a very important role for local to regional climate variability but has a rather small impact on large-scale climate conditions may be surprising since the changes in heat fluxes are some of the largest in the entire world. However, the position of the Barents Sea at the northeastern end of the North Atlantic storm track could be a reason that sea ice variations in the Barents Sea can only slightly modulate the storm track and the large-scale atmospheric circulation. Nevertheless, sea ice in the Barents Sea shows a high potential for climate predictability of the surrounding regions. This is particularly important because sea ice cover can easily be observed from satellites.

Acknowledgments This work was supported by the Deutsche Forschungsgemeinschaft through the Sonderforschungsbereich 512. The computations have been performed by the Deutsches Klima Rechenzentrum (DKRZ).

Open Access This article is distributed under the terms of the Creative Commons Attribution Noncommercial License which permits any noncommercial use, distribution, and reproduction in any medium, provided the original author(s) and source are credited. 


\section{References}

Alexander M, Bhatt U, Walsh J, Timlin M, Miller J, Scott J (2004) The atmospheric response to realistic Arctic sea ice anomalies in an AGCM during winter. J Clim 17:890-905. doi :10.1175/15200442(2004)017<0890:TARTRA > 2.0.CO;2

Bengtsson L, Semenov VA, Johannessen OM (2004) The early twentieth-century warming in the Arctic-a possible mechanism. J Clim 17:4045-4057. doi :10.1175/1520-0442(2004) 017<4045:TETWIT $>2.0$. CO; 2

Delworth TL, Manabe S, Stouffer RJ (1997) Multidecadal climate variability in the Greenland Sea and surrounding regions: a coupled model study. Geophys Res Lett 24(3):257-260. doi:10.1029/96GL03927

Deser C, Walsh J, Timlin M (2000) Arctic sea ice variability in the context of recent atmospheric circulation trends. J Clim 13:607633

Deser C, Magnusdottir G, Saravanan R, Philipps A (2004) The effects of North Atlantic SST and sea ice anomalies on the winter circulation in CCM3, Part II: direct and indirect components of the response. J Clim 17:877-889. doi :10.1175/1520-0442(2004) $017<0877$ :TEONAS $>2.0 . \mathrm{CO} ; 2$

Divine DD, Dick C (2006) Historical variability of sea ice edge position in the Nordic Seas. J Geophys Res 111:C01001. doi: 10.1029/2004JC002851

Drinkwater KF (2006) The regime shift of the $1920 \mathrm{~s}$ and $1930 \mathrm{~s}$ in the North Atlantic. Prog Oceanogr 68:134-151. doi: 10.1016/j.pocean.2006.02.011

Eden C, Jung T (2001) North Atlantic interdecadal variability: oceanic response to the North Atlantic oscillation (1865-1997). J Clim 14:676-691. doi :10.1175/1520-0442(2001)014<0676: NAIVOR $>2.0 . \mathrm{CO} ; 2$

Eden C, Willebrand J (2001) Mechanism of interannual to decadal variability of the North Atlantic circulation. J Clim 14:2266-2280. doi :10.1175/1520-0442(2001)014<2266:MOITDV>2.0.CO;2

Furevik T (2001) Annual and interannual variability of Atlantic water temperatures in the Norwegian and Barents Seas: 1980-1996. Deep Sea Res Part I Oceanogr Res Pap 48:383-404. doi: 10.1016/S0967-0637(00)00050-9

Goosse H, Holland MM (2005) Mechanisms of decadal Arctic Climate variability in the community climate system model, version 2 (CCSM2). J Clim 18:3552-3570. doi:10.1175/JCLI3476.1

Goosse H, Selten F, Haarsma R, Opsteegh J (2002) A mechanism of decadal variability of the sea-ice volume in the Northern Hemisphere. Clim Dyn 19:61-83. doi:10.1007/s00382-0010209-5

Goosse H, Selten FM, Haarsma RJ, Opsteegh JD (2003) Large sea ice volume anomalies simulated in a coupled climate model. Clim Dyn 20:523-536

Hagemann S, Dümenil L (1998) A parameterisation of the lateral waterflow for the global scale. Clim Dyn 14(1):17-31. doi: 10.1007/s003820050205

Hagemann S, Dümenil-Gates L (2003) Improving a subgrid runoff parameterisation scheme for climate models by the use of high resolution data derived from satellite observations. Clim Dyn 21(3-4):349-359. doi:10.1007/s00382-003-0349-x

Hibler WD (1979) A dynamic-thermodynamic sea ice model. J Phys Oceanogr 9(4):815-846. doi :10.1175/1520-0485(1979)009< 0815:ADTSIM $>2.0 . \mathrm{CO} ; 2$

Hilmer M, Lemke P (2000) On the decrease of Arctic sea ice volume. Geophys Res Lett 27(7):3751-3754. doi:10.1029/2000GL0 11403

Holland M (2003) The North Atlantic oscillation-Arctic oscillation in the CCSM2 and its influence on Arctic climate variability.
J Clim 16:2767-2781. doi :10.1175/1520-0442(2003)016<2767: TNAOOI $>2.0 . \mathrm{CO} ; 2$

Holland M, Bitz C (2003) Polar amplification of climate change in coupled models. Clim Dyn 21:221-232. doi:10.1007/ s00382-003-0332-6

Houssais MN, Herbaut C, Schlichtholz P, Rousset C (2007) Arctic salinity anomalies and their link to the North Atlantic during a positive phase of the Arctic oscillation. Prog Oceanogr 73(2):160-189. doi:10.1016/j.pocean.2007.02.005

Johannessen OM, Myrmehl C, Olsen AM, Hamre T (2002) Ice cover data analysis-Arctic. AICSEX Tech Rep 2. Nansen Environ. and Remote Sens. Cent, Bergen

Jungclaus JH, Haak H, Latif M, Mikolajewicz U (2005) Arctic-North Atlantic interactions and multidecadal variability of the meridional overturning circulation. J Clim 18(19):4016-4034. doi: 10.1175/JCLI3462.1

Jungclaus JH, Botzet M, Haak H, Keenlyside N, Luo JJ, Latif M et al (2006) Ocean circulation and tropical variability in the coupled model ECHAM5/MPI-OM. J Clim 19:3952-3972. doi: 10.1175/JCLI3827.1

Kalnay E, Kanamitsu M, Kistler R, Collins W, Deaven D, Gandin L et al (1995) The NCEP/NCAR 40-year reanalysis project. Bull Am Meteorol Soc 77(3):437-471. doi :10.1175/1520-0477 (1996) $077<0437$ :TNYRP $>2.0 . C O ; 2$

Keup-Thiel E, Göttel H, Jacob D (2006) Regional climate simulations for the Barents Sea region. Boreal Environ Res 11:329-339

Kimura N, Wakatsuchi M (2001) Mechanism for the variation of sea ice extent in the Northern Hemisphere. J Geophys Res 106(C12):31319-31331. doi:10.1029/2000JC000739

Koenigk T, Mikolajewicz U, Haak H, Jungclaus J (2006) Variability of Fram Strait sea ice export: causes, impacts and feedbacks in a coupled climate model. Clim Dyn 26:17-34. doi:10.1007/ s00382-005-0060-1

Koenigk T, Mikolajewicz U, Haak H, Jungclaus J (2007) Arctic Freshwater Export in the 20th and 21st Century. J Geophys Res 112:GS04S41. doi:10.1029/2006JG000274

Koenigk T, Mikolajewicz U, Haak H, Jungclaus J (2008) Modeling the sea ice export through Fram Strait. In: Dickson B, Meincke J, Rhines P (eds) Arctic-Subarctic ocean fluxes: defining the role of the northern seas in climate, Chap. 8. Springer, Berlin

Kvamstö NG, Skeie P, Stephenson DB (2004) Large-scale impact of localized Labrador sea-ice changes on the North Atlantic oscillation. Int J Climatol 24:603-612. doi:10.1002/joc.1015

Kwok R, Maslowski W, Laxon SW (2005) On large outflows of Arctic sea ice into the Barents Sea. Geophys Res Lett 32:L22503. doi:10.1029/2005GL024485

Laine V (2004) Arctic sea ice regional albedo variability and trends, 1982-1998. J Geophys Res 109, C06027, doi:10.1029/ 2003JC001818

Liu J, Curry JA, Hu Y (2004) Recent Arctic Sea Ice Variability: Connection to the Arctic Oscillation and the ENSO. Geophys Res Lett 31, L09211, doi:10.1029/2004GL019858

Magnusdottir G, Deser C, Saravanan R (2004) The Effects of North Atlantic SST and Sea Ice Anomalies on the Winter Circulation in CCM3. Part I: Main Features and Storm Track Characteristics of the Response. J Clim 17(5):857-876. doi :10.1175/15200442(2004)017<0857:TEONAS $>2.0 . \mathrm{CO} ; 2$

Marsland S, Haak H, Jungclaus J, Latif M, Roeske F (2003) The MaxPlanck-Institute global ocean/sea ice model with orthogonal curvilinear coordinates. Ocean Model 5:91-127. doi:10. 1016/S1463-5003(02)00015-X

Mysak L, Venegas S (1998) Decadal climate oscillations in the Arctic: a new feedback loop for atmosphere-ice-ocean interactions. Geophys Res Lett 25(19):3607-3610. doi:10.1029/ 98GL02782 
Overland JE, Wang, M (2005) The Arctic climate paradox: The recent decrease of the Arctic Oscillation. Geophys Res Lett 32. doi: 10.1029/2004GL021752

Parkinson CL, Cavalieri DJ, Gloersen P, Zwally HJ (1999) Arctic sea ice extents, areas, and trends, 1978-1996. J Geophys Res-Oceans 104 (C9):20837-20856

Polyakov I, Johnson M (2000) Arctic decadal and interdecadal variability. Geophys Res Lett 27(24):4097-4100

Rinke A, Maslowski W, Dethloff K, Clement J (2006) Influence of sea ice on the atmosphere: A study with an Arctic atmospheric regional climate model. J Geophys Res 111(D16103). doi:10.1029/2005JD006957

Roeckner E, Baeuml G, Bonaventura L, Brokopf R, Esch M, Giorgetta M, Hagemann S, Kirchner I, Kornblueh L, Manzini E, Rhodin A, Schlese U, Schulzweida U, Tompkins A (2003) The atmosphere general circulation model ECHAM5, part 1: Model description. Max-Planck-Institut für Meteorologie, Report No. 349: $127 \mathrm{pp}$

Shapiro I, Colony R, Vinje T (2003) April sea ice extent in the Barents Sea, 1850-2001. Polar Res 22(1):5-10

Simonsen K, Haugan PM (1996) Heat budgets of the Arctic Mediterranean and sea surface heat flux parameterizations for the Nordic Seas. J Geophys Res 101:6553-6576

Singarayer JS, Bamber JL, Valdes PJ (2006) Twenty-first-century climate impacts from a declining Arctic sea ice cover. J Clim 19(7): 1109-1125, doi:10.1175/JCLI3649.1
Sorteberg A, Kvingedal B (2006) Atmospheric forcing on the Barents Sea winter ice extent. J Clim 19:4772-4787

Sundby S, Drinkwater K (2007) On the mechanisms behind salinity anomaly signals of the northern North Atlantic. Progr. Ocean. 73 (2):190-202. doi:10.1016/j.pocean.2007.02.002

Valcke S, Caubel A, Declat D, Terray L (2003) OASIS Ocean Atmosphere Sea Ice Soil user's guide. CERFACS, Tech. Rep. TR/GMGC/03/69, Toulouse, France, p 85

Vinje $T$ (2001) Anomalies and trends of sea-ice extent and atmospheric circulation in the Nordic Seas during the period 1864-1998. J Clim 14(3):255-267

Wang J, Wu B, Tang CCL, Walsh JE, Ikeda M (2004) Seesaw structure of subsurface temperature anomalies between the Barents Sea and the Labrador Sea. Geophys Res Lett 31:L19301. doi:10.129/2004GL019981

Wu B, Wang J, Walsh J (2004) Possible feedback of Winter Sea Ice in the Greenland and Barents Sea on the local atmosphere. Mon Wea Rev 132:1868-1876

Yamamoto K, Tachibana Y, Honda M, Ukita J (2006) Intra-seasonal relationship between the Northern Hemisphere sea ice variability and the North Atlantic Oscillation. Geophys Res Lett 33:L14711. doi:10.1029/2006GL026286 